\title{
Connexin45-Containing Neuronal Gap Junctions in Rodent Retina Also Contain Connexin36 in Both Apposing Hemiplaques, Forming Bihomotypic Gap Junctions, with Scaffolding Contributed by Zonula Occludens-1
}

\author{
Xinbo Li, ${ }^{1 \star}$ Naomi Kamasawa, ${ }^{2,3 *}$ Cristina Ciolofan, ${ }^{1}$ Carl 0. Olson, ${ }^{1}$ Shijun Lu, ${ }^{1}$ Kimberly G. V. Davidson, ${ }^{3}$ \\ Thomas Yasumura, ${ }^{3}$ Ryuichi Shigemoto, ${ }^{2}$ John E. Rash, ${ }^{3,4}$ and James I. Nagy ${ }^{1}$ \\ ${ }^{1}$ Department of Physiology, Faculty of Medicine, University of Manitoba, Winnipeg, Manitoba, Canada R3E 3J7, ${ }^{2}$ Division of Cerebral Structure, National \\ Institute for Physiological Sciences, Okazaki 444-8787, Japan, and ${ }^{3}$ Department of Biomedical Sciences and 4 Program in Molecular, Cellular, and Integrative \\ Neurosciences, Colorado State University, Fort Collins, Colorado 80523
}

\begin{abstract}
Mammalian retinas contain abundant neuronal gap junctions, particularly in the inner plexiform layer (IPL), where the two principal neuronal connexin proteins are $\mathrm{Cx} 36$ and $\mathrm{Cx} 45$. Currently undetermined are coupling relationships between these connexins and whether both are expressed together or separately in a neuronal subtype-specific manner. Although Cx45-expressing neurons strongly couple with $\mathrm{Cx} 36$-expressing neurons, possibly via heterotypic gap junctions, $\mathrm{Cx} 45$ and $\mathrm{Cx} 36$ failed to form functional heterotypic channels in vitro. We now show that $\mathrm{Cx} 36$ and $\mathrm{Cx} 45$ coexpressed in HeLa cells were colocalized in immunofluorescent puncta between contacting cells, demonstrating targeting/scaffolding competence for both connexins in vitro. However, Cx36 and Cx45 expressed separately did not form immunofluorescent puncta containing both connexins, supporting lack of heterotypic coupling competence. In IPL, 87\% of Cx45immunofluorescent puncta were colocalized with $\mathrm{Cx} 36$, supporting either widespread heterotypic coupling or bihomotypic coupling. Ultrastructurally, Cx45 was detected in 9\% of IPL gap junction hemiplaques, 90-100\% of which also contained Cx36, demonstrating connexin coexpression and cotargeting in virtually all IPL neurons that express $\mathrm{Cx} 45$. Moreover, double replicas revealed both connexins in separate domains mirrored on both sides of matched hemiplaques. With previous evidence that $\mathrm{Cx} 36$ interacts with PDZ1 domain of zonula occludens-1 (ZO-1), we show that $\mathrm{Cx} 45$ interacts with PDZ2 domain of ZO-1, and that $\mathrm{Cx} 36, \mathrm{Cx} 45$, and ZO-1 coimmunoprecipitate, suggesting that ZO-1 provides for coscaffolding of $\mathrm{Cx} 45$ with $\mathrm{Cx} 36$. These data document that in $\mathrm{Cx} 45$-expressing neurons of IPL, $\mathrm{Cx} 45$ is almost always accompanied by $\mathrm{Cx} 36$, forming "bihomotypic" gap junctions, with $\mathrm{Cx} 45$ structurally coupling to $\mathrm{C} \times 45$ and $\mathrm{Cx} 36$ coupling to $\mathrm{Cx} 36$.
\end{abstract}

Key words: double replica; FRIL; heterotypic coupling; homotypic coupling; PDZ domains; SDS-FRL

\section{Introduction}

In the retinal inner plexiform layer (IPL), rod and cone pathways are linked to output ganglion cells via abundant gap junctions

Received May 8, 2008; revised July 17, 2008; accepted Aug. 13, 2008.

This work was supported by grants from the Canadian Institutes of Health Research (J.I.N.), by National Institutes of Health Grants NS31027, NS44010, and NS44395 (J.E.R.), and by Solution-Oriented Research for Science and Technology, Japan Science and Technology Agency (R.S.). We thank B. McLean for excellent technical assistance, Dr. D. Paul (Harvard University, Cambridge, MA) for providing a breeding pair of $\mathrm{C} \times 36^{+/-}$mice, Dr. B. Giepmans (University of California, San Diego, La Jolla, CA) for providing GST-PDZ expression vectors, and Dr. K. Willecke (University of Bonn, Bonn, Germany) for providing HeLa cells stably transfected with Cx43 and Cx45. We thank Dr. J. zumBrunnen (Department of Statistics, Colorado State University, Fort Collins, $\mathrm{CO}$ ) for assistance in determination of confidence intervals.

*X.L. and N.K. contributed equally to this work.

Correspondence should be addressed to either of the following: Dr. John E. Rash, Department of Biomedical Sciences, Colorado State University, Fort Collins, C0 80523, E-mail: john.rash@colostate.edu (regarding FRIL); or Dr. James I. Nagy, Department of Physiology, Faculty of Medicine, University of Manitoba, 730 William Avenue, Winnipeg, Manitoba, Canada R3E 3J7, E-mail: nagyji@ms.umanitoba.ca (regarding immunofluorescence, molecular approaches, and cell culture).

S. Lu's present address: Department of Pathology, Weifang Medical College, Weifang Shandon 261042, People's Republic of China.

DOI:10.1523/JNEUROSCI.2137-08.2008

Copyright $\odot 2008$ Society for Neuroscience $\quad$ 0270-6474/08/289769-21\$15.00/0
(Kolb, 1979; Vaney and Weiler, 2000). Of 20 gap junctionforming connexin proteins in the mouse genome (Söhl et al., 2005), mRNA or protein for only two connexins, Cx36 and Cx45, are detected in neurons of mouse IPL (Güldenagel et al., 2000; Feigenspan et al., 2001; Maxeiner et al., 2005). Cx36-containing junctions, in particular, exhibit large-scale ultrastructural diversity (Kamasawa et al., 2006), with different forms correlated with different complements of the gap junction scaffolding and regulatory proteins zonula occludens-1 (ZO-1), ZO-2, and ZO-1associated nucleic acid binding protein (ZONAB) (Balda et al., 2003; Ciolofan et al., 2006). However, ultrastructural associations of $\mathrm{Cx} 45$ with $\mathrm{Cx} 36$, morphologies of $\mathrm{Cx} 45$-containing gap junctions, and identities of $\mathrm{Cx} 45$-associated scaffolding proteins are not established.

Identifying connexins expressed in each neuronal subtype and defining connexin pairing relationships is critical to understanding how, at low light intensity, rod pathways couple via gap junctions to cone bipolar pathways through AII amacrine cell intermediaries (Kolb and Famiglietti, 1974; Vaney and Weiler, 2000; Deans et al., 2002). Initial studies to determine connexin expres- 
Table 1. Antibodies used for Western blotting and immunohistochemistry

\begin{tabular}{|c|c|c|c|c|c|}
\hline Antibody & Type & Species & Epitope; designation & Dilution ( $\mu \mathrm{g} / \mathrm{ml})$ & Source \\
\hline$C \times 36$ & Polyclonal & Rabbit & C terminus; $36-4600$ & 1 & Invitrogen \\
\hline Cx36 & Polyclonal & Rabbit & Midregion; 51-6300 & 4 & Invitrogen \\
\hline$C \times 36$ & Monoclonal & Mouse & Midregion; 37-4600 & 3 & Invitrogen \\
\hline$C \times 36$ & Monoclonal & Mouse & C terminus; $39-4200$ & 4 & Invitrogen \\
\hline Cx43 & Polyclonal & Rabbit & C terminus; $71-0700$ & 2 & Invitrogen \\
\hline Cx45 & Polyclonal & Rabbit & C terminus; $40-7000$ & 2 & Invitrogen \\
\hline Cx45 & Monoclonal & Mouse & C terminus; $41-1700$ & 2 & Invitrogen \\
\hline Cx45 & Monoclonal & Mouse & aa $354-367 ;$ MAB3101 & 4 & Millipore Bioscience Research Reagents \\
\hline Z0-1 & Polyclonal & Rabbit & aа $463-1109 ; 61-7300$ & 1 & Invitrogen \\
\hline Z0-1 & Monoclonal & Mouse & aа $334-634 ; 33-9100$ & 4 & Invitrogen \\
\hline ZO-2 & Monoclonal & Mouse & aa 87-208; Ab611561 & 3 & BD Biosciences \\
\hline ZONAB & Polyclonal & Rabbit & C terminus; $40-2800$ & 2 & Invitrogen \\
\hline GST & Polyclonal & Rabbit & Whole protein; Ab06-332 & 1 & Millipore \\
\hline
\end{tabular}

aa, Amino acids.

sion patterns used in situ hybridization and single-cell reverse transcription (RT)-PCR for connexin mRNA detection, or used the promoter sequences for $\mathrm{Cx} 45$ and $\mathrm{Cx} 36$ to drive expression of either lacZ ( $\beta$-galactosidase) or enhanced green fluorescent protein (EGFP). The results appeared to demonstrate that many neurons express either $\mathrm{Cx} 36$ or $\mathrm{Cx} 45$, but coexpression of these connexins was not detected in any retinal neurons (Han and Massey, 2005; Schubert et al., 2005; Söhl et al., 2005; Dedek et al., 2006), except minimally in one study (Lin et al., 2005). Further, Han and Massey (2005) reported that "cx45 immunopuncta never colocalize with cx36 puncta" and suggested that Cx36 and Cx45 form separate populations of homotypic gap junctions. In contrast, Dedek et al. (2006) reported that $30 \%$ of Cx45immunopositive puncta were colocalized with Cx36 and proposed those puncta to represent heterotypic Cx36-to-Cx45 gap junctions, which could account for abundant electrical and tracer coupling of neurons separately expressing Cx36 versus Cx45 (Maxeiner et al., 2005). That proposal raised difficulties because dye-coupling evidence suggested that $\mathrm{Cx} 36$ and $\mathrm{Cx} 45$ are unable to form functional heterotypic channels in HeLa cells (Teubner et al., 2000), which led to the suggestion that HeLa cells may lack essential coupling factors that otherwise permit proposed heterotypic coupling of these connexins between IPL neurons (Dedek et al., 2006).

The above discrepancies led us to investigate neuronal gap junctions in rodent IPL according to connexin composition, ultrastructural configurations, and complement of gap junction scaffolding and regulatory proteins ZO-1, ZO-2, and ZONAB. We then analyzed $\mathrm{Cx} 36 / \mathrm{Cx} 45 / \mathrm{ZO}-1$ cellular localization and molecular interactions in HeLa expression systems and in mouse retina using coimmunoprecipitation (co-IP) and pull-down assays. Finally, we used freeze-fracture replica immunogold labeling (FRIL) (Rash et al., 2001) and SDS-digested freeze-fracture replica labeling (SDS-FRL) (Fujimoto, 1995) to colocalize Cx45 and Cx36 in hemiplaques of ultrastructurally defined gap junctions, including in double replicas of the same gap junctions. Our results reveal that most if not all $\mathrm{Cx} 45$-containing gap junction hemiplaques also contain Cx36, forming Cx36-to-Cx36 plus Cx45-to-Cx45 bihomotypic gap junctions.

\section{Materials and Methods}

Antibodies and animals. Antibodies, their sources, and conditions under which they were used in this study are presented in Table 1. Most antibodies were obtained from Invitrogen, including a recently available polyclonal antibody generated against a peptide corresponding to a sequence within the $\mathrm{C}$ terminus region of mouse $\mathrm{Cx} 45$. Mouse monoclonal anti-Cx45 was also obtained from Millipore Bioscience Research Re- agents. Specificities of the anti-Cx36, anti-ZO-1, anti-ZO-2, and antiZONAB antibodies have been demonstrated previously (Li et al., 2004a; Penes et al., 2005; Ciolofan et al., 2006). Rabbit anti-glutathione S-transferase (GST) Ab06-332 for detection of GST-PDZ domain fusion proteins was obtained from Millipore. Monoclonal and polyclonal antiFLAG antibodies used as control IgGs in coimmunoprecipitation studies were obtained from Sigma-Aldrich. For immunocytochemical studies, we used 35 adult male CD1 mice, five male C57BL6/129SvEv wild-type and five Cx36 knock-out (ko) mice. For FRIL, we used five adult male and five adult female mice [four albino mice expressing GFP in locus ceruleus neurons (van den Pol et al., 2002; Rash et al., 2007b) (mice courtesy of Dr. Anthony van den Pol, Yale University, New Haven, CT), five C57BL, and one CL3], plus three adult male Sprague Dawley rats. One Wistar rat was used for SDS-FRL double replicas. All experiments were conducted according to protocols approved by our respective institutional Animal Care Committees, as prescribed in the Principles of Laboratory Animal Care (National Institutes of Health publication No. 8623, revised 1985), with minimization of stress to animals and minimization of the number of animals used.

Light microscope immunohistochemistry. Mice deeply anesthetized with equithesin $(3 \mathrm{ml} / \mathrm{kg})$ under photopic conditions were transcardially perfused with $3 \mathrm{ml}$ of cold $50 \mathrm{~mm}$ sodium phosphate buffer, $\mathrm{pH}$ 7.4, containing $0.9 \% \mathrm{NaCl}, 0.1 \mathrm{M}$ sodium nitrite, and $1 \mathrm{U} / \mathrm{ml}$ heparin, and then with $40 \mathrm{ml}$ of cold $0.16 \mathrm{M}$ sodium phosphate buffer, $\mathrm{pH}$ 7.6, containing $1 \%$ formaldehyde and $0.2 \%$ picric acid. To ascertain the extent to which the total exposure to weak formaldehyde alters detectability of connexins, additional mice were perfused with half as much fixative for half the time. In both cases, residual fixative was immediately flushed from animals by perfusion with $10 \mathrm{ml}$ of $25 \mathrm{~mm}$ sodium phosphate buffer, $\mathrm{pH}$ 7.4, containing $10 \%$ sucrose, thereby terminating further formaldehyde exposure. By comparison, other laboratories routinely fix via perfusion with $4 \%$ formaldehyde for $10 \mathrm{~min}$ (Maxeiner et al., 2005), immersion of Vibratome slices of retina in 4\% formaldehyde for $10 \mathrm{~min}$ (Güldenagel et al., 2000), or immersion of isolated retinas in $4 \%$ formaldehyde for 30 $\min$ (Lin et al., 2005). These differences may be important because some investigators detected no Cx45 immunofluorescence in the OFF sublamina of IPL (Güldenagel et al., 2000), whereas other groups detected Cx45 in OFF sublamina and greater density of puncta in ON sublamina (Han and Massey, 2005).

After perfusion fixation, eyes were removed, cryoprotected for 24-72 $\mathrm{h}$ in the final rinse, supplemented with sodium azide. Vertical sections of retina were cut $(10 \mu \mathrm{m})$ on a cryostat and collected on gelatinized glass slides. Sections were washed for $20 \mathrm{~min}$ in $50 \mathrm{~mm}$ Tris- $\mathrm{HCl}$, pH 7.4, containing $1.5 \%$ sodium chloride (TBS) and $0.3 \%$ Triton X-100 (TB$\mathrm{STr}$ ). For double-immunofluorescence labeling, sections were incubated simultaneously with two primary antibodies for $24 \mathrm{~h}$ at $4^{\circ} \mathrm{C}$, then washed for $1 \mathrm{~h}$ in TBSTr, and incubated for $1.5 \mathrm{~h}$ at room temperature simultaneously with appropriate combinations of secondary antibodies, which included the following: FITC-conjugated horse anti-mouse IgG diluted 1:100 (Vector Laboratories), Cy3-conjugated goat anti-mouse IgG di- 
luted 1:200 (Jackson ImmunoResearch Laboratories), Alexa Fluor 488conjugated goat anti-rabbit IgG diluted 1:1000 (Invitrogen), and Cy3conjugated donkey anti-rabbit diluted 1:200 (Jackson ImmunoResearch Laboratories). All antibodies were diluted in TBSTr containing 5\% normal goat or normal donkey serum. After secondary antibody incubations, sections were washed in TBSTr for $20 \mathrm{~min}$; in $50 \mathrm{~mm}$ Tris- $\mathrm{HCl}$ buffer, $\mathrm{pH}$ 7.4, for $30 \mathrm{~min}$; covered with antifade medium; and coverslipped. Some sections single labeled with anti-Cx45 or anti-Cx36 were counterstained with either red Nissl fluorescent NeuroTrace (stain N21482) or green Nissl NeuroTrace (stain N21480) (Invitrogen). Control procedures included omission of one of the primary antibodies with inclusion of each of the secondary antibodies to establish absence of inappropriate cross-reactions between primary and secondary antibodies or between different combinations of secondary antibodies.

For immunolabeling of HeLa cells grown on poly-L-lysine-treated glass coverslips, cells were fixed with ice-cold $1 \%$ or $2 \%$ formaldehyde for $5 \mathrm{~min}$, washed in TBS, and incubated for $16 \mathrm{~h}$ at $4^{\circ} \mathrm{C}$ simultaneously with rabbit anti-Cx45 and mouse anti-ZO-1, with mouse anti-Cx45 and rabbit anti-Cx43, or with mouse anti-Cx45 and rabbit anti-Cx36 in TBSTr containing normal donkey serum. Cultures were then washed in TBSTr for $1 \mathrm{~h}$ and incubated for $1 \mathrm{~h}$ at room temperature simultaneously with FITC-conjugated donkey anti-rabbit IgG diluted 1:200 and Cy3conjugated goat anti-mouse IgG diluted 1:400, or alternatively, with FITC-conjugated horse anti-mouse IgG diluted 1:200 and Cy3conjugated donkey anti-rabbit IgG diluted 1:400. Slides were washed for $1 \mathrm{~h}$ in TBSTr, covered with anti-fade medium, and coverslipped.

Conventional and confocal immunofluorescence images were acquired on a Zeiss Axioskop2 fluorescence microscope using Axiovision 3.0 software and on an Olympus Fluoview IX70 confocal microscope using Olympus Fluoview 2.1 software, and assembled using Adobe Photoshop CS (Adobe Systems), CorelDRAW Graphics Suite 12 (Corel), and Northern Eclipse software (Empix Imaging). Some confocal images are presented as $z$-stacks of five confocal scans at $z$ scanning intervals of 0.4 $\mu \mathrm{m}$. However, quantitative analyses of colocalization relationships involving counts of puncta immunopositive for $\mathrm{Cx} 45, \mathrm{Cx} 36, \mathrm{ZO}-1, \mathrm{ZO}-2$, and $\mathrm{ZONAB}$ in vertical sections of the IPL were conducted using single confocal scans with a $60 \times$ oil-immersion objective lens and a digital zoom magnification of $4 \times$ or $5 \times$. Counts were obtained from $4-10$ separate, randomly selected fields along a lateral span of $55 \mu \mathrm{m}$ encompassing the inner to outer edge of the IPL in retinas from two to four mice. Values for percentage colocalization were determined for each field and expressed as mean \pm SEM. Numbers of Cx45-positive puncta in the IPL of wild-type and Cx36 ko mice were also determined and evaluated for statistically significant differences using unpaired Student's $t$ test.

For quantitative analysis of the effects of fixation strength and duration on $\mathrm{Cx} 45$ colocalization with $\mathrm{Cx} 36$, separate datasets were collected from mice perfused with $40 \mathrm{ml}$ of the above described $1 \%$ formaldehyde/ $0.2 \%$ picric acid fixative and compared with that obtained from mice perfused with $20 \mathrm{ml}$ of the same fixative, with residual fixative immediately flushed in both cases. Double labeling was conducted using monoclonal anti-Cx45 (Millipore Bioscience Research Reagents) in combination with either polyclonal anti-Cx36 51-6300 or 36-4600 (Invitrogen), or alternatively, using polyclonal anti-Cx45 (Invitrogen) with monoclonal anti-Cx36 37-4600 (Invitrogen). As data obtained with these alternative antibody combinations were not significantly different, data were pooled. Because many Cx45-positive puncta (labeled green) in images of IPL were very small, overlay of these images with those of Cx36 (labeled red) were, in cases of $\mathrm{Cx} 45 / \mathrm{Cx} 36$ colocalization, often insufficient to produce readily discernible yellow puncta that result from spatial overlap of green and red pixels, hence reducing confidence of establishing degree of colocalization by counting yellow puncta in superimposed images. Instead, quantitative data were acquired by transferring the locations of green Cx45-puncta onto transparencies and overlaying these transparencies onto images of red puncta representing the more abundant labeling for Cx36.

As a further test for $\mathrm{Cx} 36 / \mathrm{Cx} 45$ colocalization in the retina versus simply coincidental overlap of these connexins resulting from the very high density of Cx36 in the IPL, images of Cx36 from the same field double labeled for Cx45 and Cx36 were flipped horizontally (Han and
Massey, 2005), and Cx45-puncta overlapping with Cx36-puncta were again counted.

FRIL and SDS-FRL. SDS-FRL (Fujimoto, 1995, 1997) and FRIL [originally named by Gruijters et al. (1987); as modified by Rash and Yasumura (1999) and Rash et al. (2001)] provide for high-resolution immunocytochemical identification of membrane proteins and simultaneous ultrastructural visualization of those proteins in distinctive membrane arrays. SDS detergent, as used in both FRIL and SDS-FRL, does not wash away many cytoplasmic scaffolding proteins that are strongly bonded to target transmembrane proteins in platinum/carboncoated replicas, allowing cadherins, catenins, ZO-1, ZO-2, ZONAB, and PSD-95 to be immunogold labeled and localized to tight junctions, gap junctions, adherens junctions, and postsynaptic densities (Fujimoto, 1995; Fujimoto et al., 1997; Ciolofan et al., 2006; Kamasawa et al., 2006). We used SDS-FRL for preparation of matched double replicas (see below) and FRIL for preparation of noncomplementary replicas. FRIL combines SDS-FRL with Lexan stabilization (Steere and Erbe, 1983) and "confocal grid-mapped freeze fracture" (Rash et al., 1995, 1997) for precise histological and ultrastructural mapping of immunogold-labeled gap junctions over square millimeter areas of complex CNS tissues.

For FRIL experiments, both mice and rats were used because previous immunofluorescence studies compared data from both species and reported minor but potentially significant species-specific differences (Feigenspan et al., 2001). In addition, we have published a large FRIL database characterizing distributions and morphologies of >2100 Cx36containing gap junctions in the IPL of rats and $>600 \mathrm{Cx} 36$-containing gap junctions in IPL of mice, establishing the value of both species for comparative ultrastructural and immunocytochemical analyses under a variety of illumination conditions (Kamasawa et al., 2006). Mice and rats were deeply anesthetized with ketamine/xylazine and fixed by transcardiac perfusion with $2 \%$ or $4 \%$ formaldehyde, as described previously (Kamasawa et al., 2006). After dissection and collection of Vibratome sections cut at $150 \mu \mathrm{m}$, retina specimens were cryoprotected with $30 \%$ glycerol, frozen, freeze-fracture replicated, washed with SDS detergent (Fujimoto, 1995), and immunogold labeled, as described previously (Rash et al., 2001; Kamasawa et al., 2006).

For FRIL, the same antibodies used for light microscopy (above) were diluted to $10 \mu \mathrm{g} / \mathrm{ml}$ and applied for $1.2-3 \mathrm{~h}$ at either 8 or $22^{\circ} \mathrm{C}$, and secondary antibodies were diluted 1:100 and applied for 11-15 $\mathrm{h}$ at either 8 or $22^{\circ} \mathrm{C}$. We found that this level of dilution, along with an improved "labeling blocking buffer" (Dinchuk et al., 1987) significantly decreases "background," with only minimal decrease in labeling efficiency (LE), yielding signal-to-noise ratios $>15,000: 1$ (Meier et al., 2004). The resulting relatively low labeling efficiency $(\mathrm{LE}=1: 10$ to $1: 30$, or one gold bead per 10-30 connexons) has the dual advantage that gold labels are sufficiently dispersed that they do not resemble "clumps" of gold beads resulting from aggregation of primary or secondary antibodies (Rash and Yasumura, 1999). All commercial antibodies received over the past 10 years and examined electron microscopically immediately after receipt ( $>700$ different aliquots) had low to moderate numbers and sizes of antibody clumps (data not shown), thereby potentially confounding counts of separate immunogold labels, especially in heavily labeled samples. Regardless, FRIL and SDS-FRL both allow identification of antibody clumps and determination of whether or not clumps occur on ultrastructurally identified gap junctions versus randomly within the neuropil.

To increase immunogold labeling efficiency, thereby potentially increasing detection of one or more connexins in "miniature" gap junctions (i.e., those containing $<100$ connexons) (Rash et al., 2007b), particularly those containing both $\mathrm{Cx} 36$ and $\mathrm{Cx} 45$, a second set of replicas (see Table 3 ) was labeled for $4.4-5.3 \mathrm{~h}$ in primary (vs our normal $1.2-3 \mathrm{~h}$ ) and for $22 \mathrm{~h}$ in secondary (vs 11-15 h) antibodies. By way of comparison, previous light microscopic immunocytochemical studies labeled samples with primary antibodies overnight $(>10 \mathrm{~h})$ at $4^{\circ} \mathrm{C}$ (Dedek et al., 2006) or for as long as $3-5 \mathrm{~d}$ at $4^{\circ} \mathrm{C}$ (Han and Massey, 2005; Lin et al., 2005), and for $2-3 \mathrm{~h}$ at room temperature (Lin et al., 2005) to overnight at $4^{\circ} \mathrm{C}$ for secondary antibodies (Han and Massey, 2005; Dedek et al., 2006). Thus, FRIL experiments were at the lower concentration ranges and labeling times normally used for light microscopic and ultrastruc- 
tural immunocytochemistry. Controls included omission of $\mathrm{Cx} 45$ or Cx36 antibodies or substitution of antibodies to some other protein for one or the other connexins. No spurious gap junction labeling was observed in any controls.

Double replicas by SDS-FRL. For the technically challenging doublereplica experiments, one Wistar rat was deeply anesthetized with sodium pentobarbital $(50 \mathrm{mg} / \mathrm{kg})$ and fixed by transcardiac perfusion with warmed $2 \%$ formaldehyde, $0.85 \%$ picric acid in $0.1 \mathrm{~m}$ phosphate buffer, $\mathrm{pH}$ 7.4. Retinas were removed and embedded in $1 \%$ agarose. After collection of Vibratome sections cut at $150 \mu \mathrm{m}$, retina specimens were cryoprotected with $30 \%$ glycerol, mounted between $4.6 \mathrm{~mm}$ copper sample holders, frozen using an HPM 010 high-pressure freezing device (Leica), fractured at $-105^{\circ} \mathrm{C}$ in a $\mathrm{BAF} 060$ freeze-fracture machine (Leica), sequentially replicated with $\sim 2 \mathrm{~nm}$ of carbon, $2 \mathrm{~nm}$ of platinum, and $20 \mathrm{~nm}$ of carbon, and cleaned using $2.5 \%$ SDS, $30 \%$ sucrose in $15 \mathrm{~mm}$ Tris-buffered saline, $\mathrm{pH} 8.3$, at $80^{\circ} \mathrm{C}$ for $18 \mathrm{~h}$ [modified from Tanaka et al. (2005) and Masugi-Tokita et al. (2007)].

For SDS-washed double replicas, rabbit polyclonal anti-Cx36 antibody (Invitrogen) and mouse monoclonal anti-Cx45 antibody (Millipore Bioscience Research Reagents) were diluted to $5 \mu \mathrm{g} / \mathrm{ml}$ and applied for $3.5 \mathrm{~h}$ at $15^{\circ} \mathrm{C}$, and secondary antibody (anti-rabbit IgG $10 \mathrm{~nm}$ colloidal gold conjugated, and anti-mouse IgG $5 \mathrm{~nm}$ colloidal gold conjugated; both from BBInternational) were diluted to 1:30 and applied for $24 \mathrm{~h}$ at $15^{\circ} \mathrm{C}$. After labeling, double-replica samples were photographed using an Olympus SZH dissecting microscope equipped with a CAMEDIA C-3040ZOOM digital camera (Olympus). Complementary replicas obtained using a hinged double-replica device are mirror images in depth and angle of contour (i.e., hills opposite valleys). To facilitate precise matching of image details, including matching of connexon E-face pits with P-face intramembrane particles (IMPs) in apposed hemiplaques (Chalcroft and Bullivant, 1970), one of the complementary replicas was inverted on the specimen support, and the two matching samples were placed in the electron microscope in matching orientations.

Electron microscopy. FRIL replicas were examined at $100 \mathrm{kV}$ with a JEOL 2000 EX-II TEM equipped with a $\pm 60^{\circ}$ single-tilt stage or a JEOL 1200 EX TEM equipped with a $\pm 45^{\circ}$ single-tilt stage, and SDS-FRL double replicas were examined at $80 \mathrm{kV}$ using a JEM 1010 equipped with a $\pm 60^{\circ}$ single-tilt stage and with a JEOL 2000 EX-II operated at $100 \mathrm{kV}$. All images were photographed as stereo pairs having an $8^{\circ}$ included angle and examined stereoscopically. Digital images (20-80 MB) were obtained from electron microscope negatives using an ArtixScan 2500f digital scanning device (Microtek) or with an EPSON GT-800 digital scanning device (Seiko Epson) and processed using Photoshop CS2 (Adobe Systems). The contrast range for each image was optimized using "levels." One soft-focus stereo pair from the JEOL 1200 (see Fig. 9A) was adjusted using "unsharp mask" set with zero "tolerance". All other images were prepared without unsharp mask. Where appropriate, the contrast ranges over large areas of some images were digitally "dodged" using "brightness/contrast" functions. Slight image compressions created by photography of samples tilted for stereoscopy were corrected by using the "image distort" functions and trimmed so that the "stereo windows" appear rectangular and level.

Cx45 expression vector construction. Cx45 cDNA was obtained by reverse transcription of total RNA isolated from adult mouse brain (Li et al., 2004a,b), and the Cx45 coding sequence was amplified using oligonucleotide primers and materials purchased from Invitrogen. Primers chosen for PCR were designed according to mouse Cx45 sequence (GenBank accession number, NM_008122) and were as follows: sense primer, 5'-ATGAGTTGGAGCTTCCTGACTCGC-3'; antisense primer, 5' TTAAATCCAGACGGAGGTCTTCC-3'. PCR conditions were as follows: initial denaturation at $94^{\circ} \mathrm{C}$ for $5 \mathrm{~min}$; 35 cycles of amplification with denaturation at $94^{\circ} \mathrm{C}$ for $60 \mathrm{~s}$, annealing at $52^{\circ} \mathrm{C}$ for $60 \mathrm{~s}$, and elongation at $72^{\circ} \mathrm{C}$ for $90 \mathrm{~s}$; and final extension at $72^{\circ} \mathrm{C}$ for $10 \mathrm{~min}$ for $\mathrm{T}-\mathrm{A}$ cloning. Amplification of Cx 45 cDNA by PCR was performed in $20 \mu \mathrm{l}$ of solution containing $2 \mu \mathrm{l}$ of $10 \times$ PCR buffer, $0.8 \mu \mathrm{l}$ of $50 \mathrm{mM} \mathrm{MgCl}_{2}, 200$ $\mu \mathrm{M}$ dNTP, $100 \mathrm{ng}$ of sense and antisense primers, $1 \mathrm{U}$ of TaqDNA polymerase and $1 \mu \mathrm{l}$ of template cDNA. PCR products were separated by electrophoresis in a $1.5 \%$ agarose gel prepared using TAE buffer $(40 \mathrm{~mm}$ Tris- $\mathrm{HCl}, 0.1 \%$ acetic acid, 1 mm EDTA, pH 8.0, and 0.0004\% ethidium bromide). Separated PCR products were isolated and excised under UV illumination and purified using a gel purification kit (Qiagen). PCR products were subcloned into PCR 2.1 vector, digested with BstXI, and ligated into pcDNA3 expression vector (Invitrogen) using T4 DNA ligase (Invitrogen) according to the manufacturer's instructions. Cx45 recombinant plasmids were extracted and digested with $\mathrm{XbaI}$ to confirm insert orientation and sequenced with M13 forward and reverse primers for sequence confirmation.

Cell culture and HeLa cell transfection. HeLa cells (American Type Culture Collection), grown in DMEM supplemented with 10\% fetal bovine serum and $1 \%$ penicillin-streptomycin, were transiently transfected with pcDNA3 vector or Cx45-pcDNA3 plasmids using LipofectAMINE 2000 reagent (Invitrogen), as described previously (Li et al., 2004a,b,c). HeLa cells were similarly cotransfected with Cx45 and either full-length Cx36 or truncated $\mathrm{Cx} 36$ that lacks the $4 \mathrm{C}$-terminal amino acids representing the PDZ domain-binding motif of Cx36 [prepared as described previously (Li et al., 2004a)]. Transiently transfected HeLa cells were taken for analysis after a $24 \mathrm{~h}$ transfection period. For selection of clones stably transfected with Cx45, transfected cells were grown for $24 \mathrm{~h}$ and then

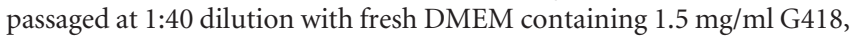
and individual clones expressing Cx45 were isolated after 3 weeks in culture. HeLa cells stably expressing Cx36 were prepared as described previously ( $\mathrm{Li}$ et al., 2004a). Cocultures of HeLa cells stably expressing Cx36, Cx43, or Cx45 (generated as above or provided to us by Dr. K. Willecke, University of Bonn, Bonn, Germany) were prepared by mixing equal numbers of $\mathrm{Cx} 43$ - and $\mathrm{Cx} 45$-expressing cells or by mixing equal numbers of Cx36- and Cx45-expressing cells at a density of $\sim 10,000$ cells per chamber $\left(1-1.5 \mathrm{~cm}^{2}\right)$ on culture slides for $2 \mathrm{~d}$ or until reaching confluence. Transient transfection of Cx45 into HeLa cells stably expressing Cx36 was conducted as described above for transfection of HeLa cells with $\mathrm{Cx} 45$.

Western blotting. Deeply anesthetized animals were decapitated, and retinas were dissected, rapidly frozen, and stored at $-80^{\circ} \mathrm{C}$ until use. Cx45-transfected and vector-control HeLa cells were rinsed with PBS buffer (50 mu sodium phosphate buffer, $\mathrm{pH} 7.4,0.9 \%$ saline), and these cells and retinas were homogenized in IP buffer (20 mM Tris-HCl, $\mathrm{pH} 8.0$, $140 \mathrm{~mm} \mathrm{NaCl}, 1 \%$ Triton X-100, 10\% glycerol, 1 mm EGTA, $1.5 \mathrm{~mm}$ $\mathrm{MgCl}_{2}, 1 \mathrm{~mm}$ dithiothreitol, $1 \mathrm{~mm}$ phenylmethylsulfonyl fluoride, and 5 $\mu \mathrm{g} / \mathrm{ml}$ each of leupeptin, pepstatin $\mathrm{A}$, and aprotinin) and sonicated. Homogenates were centrifuged at 20,000 $\times g$ for $5 \mathrm{~min}$, and the supernatants were taken for protein determination using a kit (Bio-Rad Laboratories). Western blotting was performed as described previously (Li et al., 2004a,b; Chen et al., 2006). Proteins (50-100 $\mu \mathrm{g}$ of protein per lane from tissue homogenates and $3 \mu \mathrm{g}$ per lane from culture cell lysates) were separated by SDS-PAGE using either $10 \%$ or $12.5 \%$ gels followed by transblotting to polyvinylidene difluoride membranes (Bio-Rad Laboratories) in standard Tris-glycine transfer buffer, $\mathrm{pH} 8.3$, containing $0.5 \%$ SDS. Membranes were blocked for $2 \mathrm{~h}$ at room temperature in TBSTw (10 mm Tris- $\mathrm{HCl}, \mathrm{pH} 8.0,150 \mathrm{~mm} \mathrm{NaCl}$, and $0.2 \%$ Tween 20 ) containing $5 \%$ nonfat milk powder, rinsed briefly in TBSTw, and incubated overnight at $4^{\circ} \mathrm{C}$ with anti-Cx45 in TBSTw containing $1 \%$ nonfat milk powder. Membranes were washed in TBSTw for $40 \mathrm{~min}$, incubated with horseradish peroxidase-conjugated donkey anti-rabbit IgG or antimouse IgG diluted 1:3000 to 1:5000 (Sigma-Aldrich) in TBSTw containing $1 \%$ nonfat milk powder, washed in TBST for $40 \mathrm{~min}$, and resolved by chemiluminescence (ECL; GE Healthcare).

$I P$. Mouse retinas and HeLa cell lysates were homogenized in IP buffer, sonicated, and centrifuged at $20,000 \times g$ for $10 \mathrm{~min}$ at $4^{\circ} \mathrm{C}$. After protein determination of sample supernatants, volumes containing $1 \mathrm{mg}$ of protein from mouse retina or from connexinexpressing HeLa cells were precleared for $1 \mathrm{~h}$ at $4^{\circ} \mathrm{C}$ using $20 \mu \mathrm{l}$ of protein-A-coated agarose beads (Santa Cruz Biotechnology), centrifuged at $20,000 \times \mathrm{g}$ for $10 \mathrm{~min}$ at $4^{\circ} \mathrm{C}$, and incubated with $2 \mu \mathrm{g}$ of polyclonal anti-ZO-1 antibody, $2 \mu \mathrm{g}$ of monoclonal anti-Cx45 antibody, or $2 \mu \mathrm{g}$ of polyclonal anti-Cx36 antibody for $16 \mathrm{~h}$ at $4^{\circ} \mathrm{C}$. The mixture was incubated for $1 \mathrm{~h}$ at $4^{\circ} \mathrm{C}$ with $20 \mu \mathrm{l}$ of protein-A-coated agarose beads and centrifuged at $20,000 \times g$ for $10 \mathrm{~min}$, and the pellet was washed five times with $1 \mathrm{ml}$ of wash buffer $(20 \mathrm{~mm}$ Tris- $\mathrm{HCl}, \mathrm{pH} 8.0,150$ $\mathrm{mm} \mathrm{NaCl}$, and $0.5 \% \mathrm{NP}-40)$. Samples were then mixed with an equal 

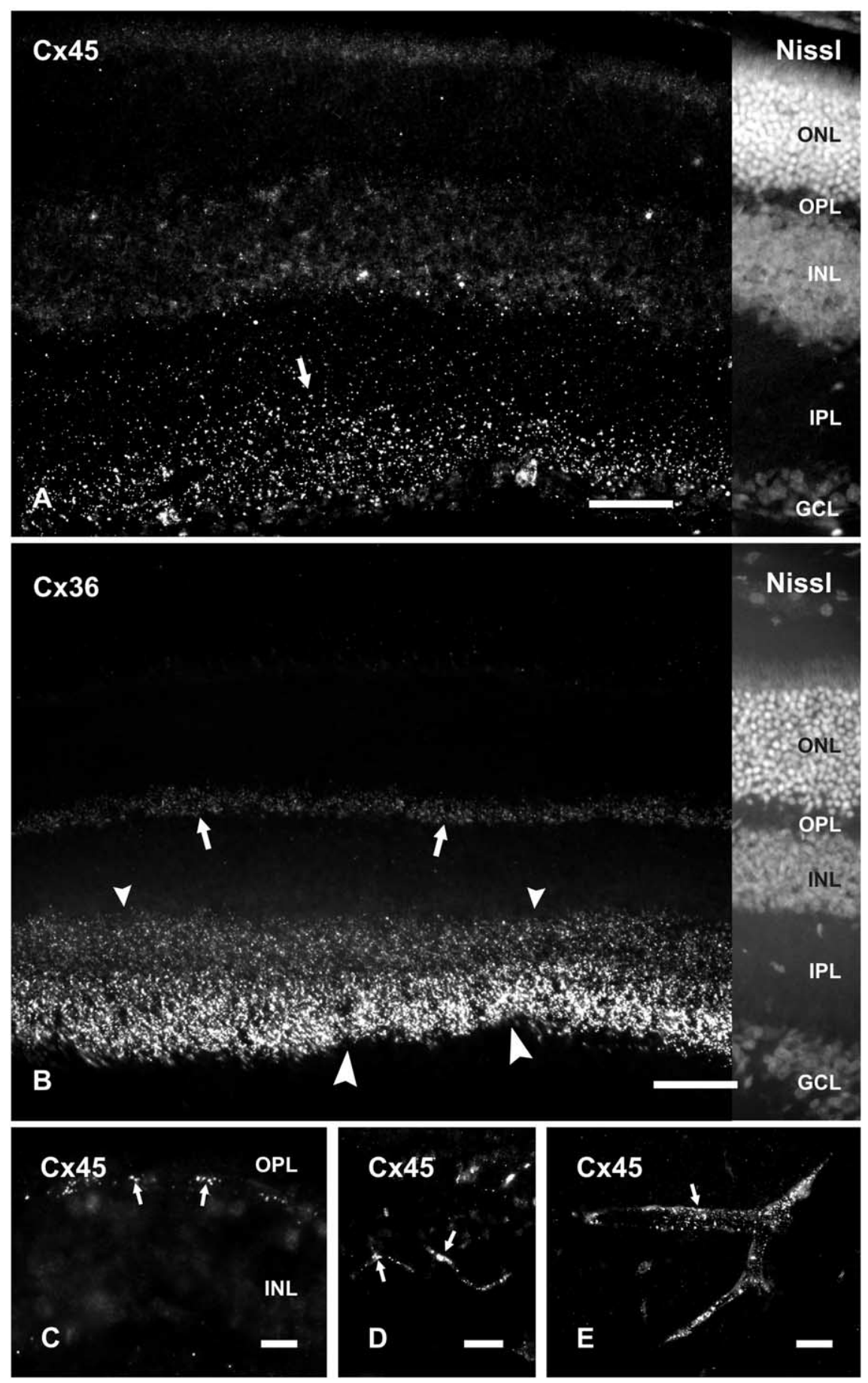

Figure 1. Immunolabeling of $\mathrm{C} \times 45$ and $\mathrm{C} \times 36$ in adult mouse retina. $A, B$, Vertical retinal sections labeled by immunofluorescence, with the right portion of each field shown by counterstaining with fluorescent NeuroTrace. Punctate labeling with polyclonal anti-Cx45 is seen in the inner half of the IPL $(\boldsymbol{A}$, arrow) and more sparsely in the outer half of the IPL $(\boldsymbol{A})$. Labeling of $C \times 36$ is very dense in the inner half of the IPL ( $\boldsymbol{B}$, large arrowheads), less dense in the outer half of the IPL ( $\boldsymbol{B}$, small arrowheads), and moderate in the OPL ( $\boldsymbol{B}$, arrows). $\boldsymbol{C}-\boldsymbol{E}$, Higher magnifications showing punctate labeling for $(x 45$ at the outer margin of the $\operatorname{INL}(\boldsymbol{C}$, arrows), along blood vessels in the retina ( $\boldsymbol{D}$, arrows), and in cerebral cortex ( $\boldsymbol{E}$, arrow). ONL, Outer nuclear layer; $G C L$, ganglion cell layer. Scale bars, $50 \mu \mathrm{m}$.

volume of SDS-PAGE loading buffer (125 mm Tris-HCl, pH 6.8, 20\% glycerol, $0.3 \mathrm{~mm}$ bromophenol blue, $0.14 \mathrm{M}$ SDS, and $20 \%$ $\beta$-mercaptoethanol). For detection of $\mathrm{Cx} 45$, samples were boiled for 5 min and taken for immunoblotting with monoclonal anti-Cx45 antibody. For detection of Cx36, samples (not boiled) were immunoblotted with polyclonal anti-Cx36 antibody. Control samples were precipitated with omission of anti-ZO-1, anti-Cx36, or anti-Cx45 antibodies.
GST-PDZ domain of ZO-1 and pull-down assays. Three $\mathrm{pGEX}-3 \mathrm{X}$ plasmids each containing one of the three GST-linked PDZ domains of ZO-1 (Nielsen et al., 2002, 2003) were kindly provided by Dr. B. Giepmans (University of California, San Diego, La Jolla, CA). Preparation of GST-PDZ fusion proteins from these plasmids expressed in Escherichia coli $\mathrm{DH} 5 \alpha$ and binding of fusion proteins to glutathioneagarose beads was conducted as described previously ( $\mathrm{Li}$ et al., 2004a,b). Beads containing PDZ domain fusion proteins were incubated for $16 \mathrm{~h}$ at $4^{\circ} \mathrm{C}$ with retina that had been homogenized in IP buffer. After extensive washing in PBS buffer containing 1\% Triton X-100, proteins from the agarose beads were eluted with SDS-PAGE loading buffer, separated by SDSPAGE, transferred to blotting membrane, and probed with anti-Cx45. After exposure to film, membranes were stripped and reprobed with anti-GST antibody for verifying equal quantities of GST-PDZ domain fusion protein loading.

\section{Results}

Distribution of $\mathrm{Cx} 45$ and $\mathrm{Cx} 36$ in retina Low-magnification images of vertical retinal sections labeled by immunofluorescence and counterstained with Nissl fluorescent NeuroTrace indicate the distributions and relative densities of $\mathrm{Cx} 45$ and $\mathrm{Cx} 36$ in mouse retina, where immunolabeling consisted exclusively of fluorescent puncta (Fig. 1). Cx45 immunofluorescence was faintly detectable in the outer plexiform layer (OPL) (Fig. 1), whereas Cx36-immunofluorescent puncta were substantially more abundant. Both monoclonal anti-Cx45 antibodies from Invitrogen and Millipore Bioscience Research Reagents, as well as polyclonal antiCx45 antibody (Fig. 1A), produced punctate labeling throughout the IPL. The polyclonal antibody produced additional sparse but robust labeling at the outer boundary of the inner nuclear layer (INL) (Fig. 1C), as well as punctate labeling along blood vessels in retina (Fig. $1 D$ ) and brain (Fig. 1E), consistent with previous descriptions of $\mathrm{Cx} 45$ distribution in rodent retina (Dedek et al., 2006) and in cerebral vasculature smooth muscle (Krüger et al., 2000; Li and Simard, 2001). The additional labeling detected with the polyclonal antibody at known tissue locations of $\mathrm{Cx} 45 \mathrm{ex}$ pression (e.g., blood vessels) suggests that the epitopes of $\mathrm{Cx} 45$ on blood vessels are not detected by the anti-Cx45 monoclonal antibodies. Labeling with each of the antiCx45 antibodies was observed using optimized fixative containing $1 \%$ formaldehyde plus $0.2 \%$ picric acid. Greater formaldehyde concentration or greater fixative volume and longer duration of fixation, each followed by washout of residual fixative, substantially suppressed both labeling density and intensity, particularly for very small Cx45-positive puncta, as determined 
by the lower density of punctate immunolabeling of Cx45 in mice perfused with 40 $\mathrm{ml}$ compared with $20 \mathrm{ml}$ of fixative (described below).

In the IPL, Cx36-positive puncta were consistently present at a higher density than Cx45-positive puncta, with the former outnumbering the latter by a ratio of $\sim 2: 1$. Using anti-Cx45 MAB3101 in combination with polyclonal anti-Cx36 antibodies in mice perfused with $20 \mathrm{ml}$ of fixative, counts of puncta yielded $736 \pm 27$ Cx36-puncta per field and $427 \pm 32$ Cx45puncta per field along a $55 \times 55 \mu \mathrm{m} x$-and $y$-axis span of the IPL, with the latter encompassing the full vertical dimensions of the IPL. Labeling for Cx45 compared with Cx36 appears much less than reflected by these numbers because of the much smaller size of $\mathrm{Cx} 45$-puncta and the presence of what appeared to be aggregates of Cx36-puncta that could not be separately resolved because of the close proximity of gap junctions in the IPL (Kolb, 1979). This almost certainly led to a vast underestimate of the number of gap junctions containing only Cx36 (Kamasawa et al., 2006), and here, to underestimates of the ratio of Cx36- to Cx45-puncta. Cx45-puncta were in greater abundance in the inner compared with the outer part of the IPL (Fig. $1 A)$. According to criteria for assigning dimensions of the IPL to inner and outer sublamina (Ghosh et al., 2004) and from counts of $\mathrm{Cx} 45$-puncta in confocal images obtained from retinas of mice, the inner three-fifths of the IPL, designated the ON sublamina, contained an average of $297 \pm$ 13 Cx45-puncta along a $55 \mu \mathrm{m} x$ - and $y$-axis span of IPL, whereas the outer twofifths, designated the OFF sublamina, contained an average of $130 \pm 31 \mathrm{Cx} 45$ puncta along the same span. Thus, the OFF sublamina has $\sim 66 \%$ of the volume density of $\mathrm{Cx} 45$ puncta as in the ON sublamina. Similar patterns of labeling for Cx45 in the IPL were obtained with polyclonal anti-Cx45. Labeling for Cx36 was densely distributed in the IPL, where it was more concentrated in the inner than the outer half, and moderately concentrated in the OPL (Fig. $1 B$ ). By way of comparison, the density of $\mathrm{Cx} 45$ puncta in the OFF sublamina in the briefly fixed samples was higher than in previously published studies, one of which reported an absence of Cx45 in the OFF sublamina (Güldenagel et al., 2000). Specifically, as reported by Dedek et al. (2006) using single confocal scans from mouse retina and using similar objective lenses as used by us, the density of $\mathrm{Cx} 45$-puncta in the OFF and ON sublamina of the IPL was 0.0128 and 0.0242 per $\mu \mathrm{m}^{2}$, respectively, whereas we found 0.043 and 0.099 per $\mu \mathrm{m}^{2}$, respectively. The density of Cx36-puncta they reported in the OFF and ON sublamina of the IPL was 0.0168 and 0.0554 per $\mu \mathrm{m}^{2}$, respectively, whereas we found 0.097 and 0.146 per $\mu \mathrm{m}^{2}$, respectively. These data indicate 3.4 -fold to 4 .1-fold difference in
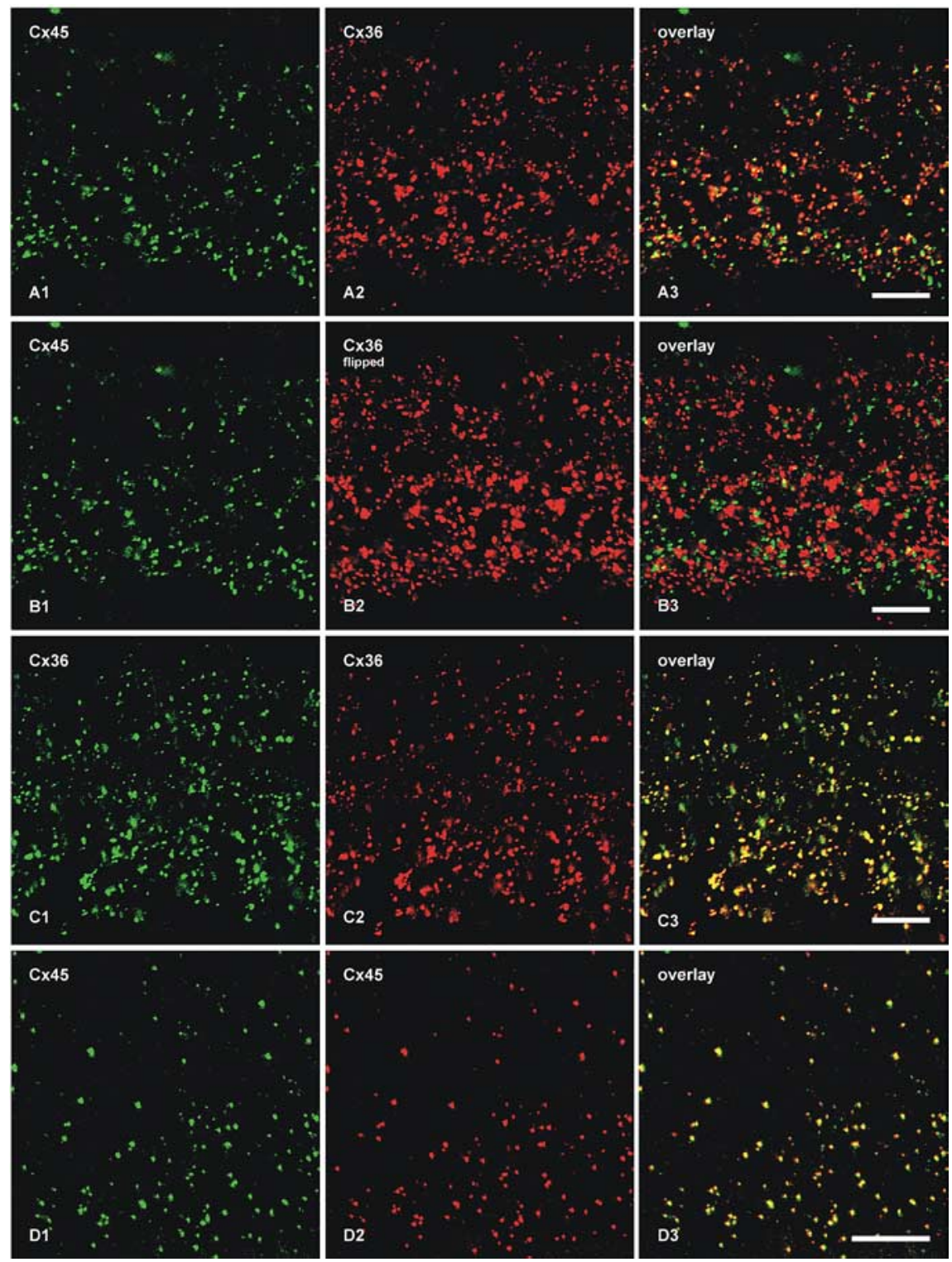

Figure 2. Double-immunofluorescence images showing colocalization of $C x 45$ with $C \times 36$ in vertical sections of the IPL of adult mouse retina. Images in $\boldsymbol{A}-\boldsymbol{D}$ show the entire vertical span of IPL in single confocal scans. $\boldsymbol{A}$, The same field $(\boldsymbol{A} \mathbf{1}-\boldsymbol{A} \mathbf{3})$ labeled with monoclonal anti- $\mathrm{C} 45$ and polyclonal anti- $\mathrm{C}$ 36, showing $C \mathrm{x} 45$-positive puncta labeled for $\mathrm{C} \times 36$ in retina after perfusion of mice colocalization in the IPL after horizontal flipping of the image showing labeling for Cx36. C, The same field (C1-C3) of IPL double labeled for Cx36 with monoclonal Ab37-4600 and polyclonal Ab36-4600, showing nearly total overlap of immunopositive puncta. D. The same field (D1-D3) in a tangential section through the IPL double labeled for Cx45 with monoclonal MAB3101 and polyclonal Ab40-7000, showing nearly total overlap of immunopositive puncta. Scale bars, $10 \mu \mathrm{m}$.

detection of immunofluorescent puncta for $\mathrm{Cx} 45$ in OFF versus ON layers of IPL and a 5.8-fold to 2.6-fold difference in detection of Cx36. This greater detection of Cx36 cannot be attributable to nonspecific immunolabeling because all immunoreactivity with anti-Cx36 antibodies we used was absent in retina of Cx36 ko mice (described below).

\section{Immunofluorescence colocalization of $\mathrm{Cx} 45$ and $\mathrm{Cx} 36$ in} the IPL

Confocal double-immunofluorescence analysis was undertaken to compare the localization of $\mathrm{Cx} 45$ with $\mathrm{Cx} 36$ in the IPL (Fig. 2). In general, most puncta immunopositive for the two connexins in the ON sublamina were larger than those in the OFF sublamina, and there appeared to be a decrease in size and density of puncta from the 
Table 2. Quantitative immunofluorescence analysis of $\mathrm{C} x 45$ colocalization relationships with $\mathrm{C} \times 36, \mathrm{Z0}-1, \mathrm{ZO}-2$, and ZONAB in the IPL of adult mouse retina

\begin{tabular}{llc}
\hline Proteins examined & $\begin{array}{l}\text { Protein } \\
\text { (total puncta counted) }^{a}\end{array}$ & $\begin{array}{l}\text { Percentage } \\
\text { colocalization }^{b}\end{array}$ \\
\hline Cx45 positive for Cx36 $^{c}$ & Cx45 (766) & $46 \pm 7.2$ \\
Cx45 positive for (x36 & Cx45 (2952) & $87 \pm 1.3$ \\
Cx45 positive for Z0-1 & Cx45 (737) & $71 \pm 2.8$ \\
Cx45 positive for ZO-2 & Cx45 (432) & $7.0 \pm 2.1$ \\
Cx45 positive for ZONAB & Cx45 (472) & $4.7 \pm 0.4$ \\
\hline
\end{tabular}

${ }^{a}$ Values in parentheses represent the total number of $\mathrm{X} \times 45$-positive or $\mathrm{Cx} 36$-positive puncta counted in 4-10 separate single-scan confocal images of the IPL in retinas from two to four mice.

${ }^{b}$ Values represent means \pm SEM.

'Data from mice prepared with $40 \mathrm{ml}$ of fixative, with immediate washout.

${ }^{d}$ Data from mice prepared with $20 \mathrm{ml}$ of fixative, with immediate washout.

ON to the OFF sublamina (Fig. 2A1,A2). Retinas from 12 mice were examined, and similar results were obtained from each. Initial quantitative confocal double-immunofluorescence analyses of $\mathrm{Cx} 45 \mathrm{co}-$ localization with $\mathrm{Cx} 36$ were conducted using retinal sections from animals transcardially perfused with $40 \mathrm{ml}$ of fixative. With this fixation protocol, $46 \%$ of $\mathrm{Cx} 45$-puncta were found to be colocalized with Cx36-puncta (Table 2), approximating the values reported by Dedek et al. (2006). Because this value was substantially lower than the extent of Cx45 colocalization with Cx36 observed by FRIL (described below), we considered the possibility that some labeling of $\mathrm{Cx} 45$ was suppressed even with the already weak tissue fixation used (data not shown). Thus, quantitative analysis was repeated using retinas from mice perfused with $20 \mathrm{ml}$ of tissue fixative, resulting in a proportional reduction in fixation time because residual fixative in all cases was flushed from animals by perfusion with buffered sucrose. This fixation protocol gave substantially greater numbers of very fine Cx45-puncta (Fig. 2A1) with both polyclonal and monoclonal anti-Cx45 antibodies than were evident with the higher volume and longer duration of fixative. In contrast to the results of Dedek et al. (2006), who found only minor overlap of Cx45 with Cx36 in the OFF sublamina of IPL, our image overlays revealed colocalization of $\mathrm{Cx} 45$ with $\mathrm{Cx} 36$ in virtually all regions of IPL, and showed that $87 \%$ of $\mathrm{Cx} 45$-puncta overlapped with Cx36-puncta (Fig. 2A, Table 2). The vast majority of these puncta showed total overlap, rather than partial overlap of adjacent puncta. Conversely, given the greater density of $\mathrm{Cx} 36$ than $\mathrm{Cx} 45$ in the IPL, most Cx36puncta were not labeled for Cx45 (not quantified).

Partially overlapping or adjacent puncta were suggested as evidence for heterotypic gap junctions, with Cx36 on one side and Cx45 on the other side (Dedek et al., 2006). However, immunofluorescence labeling for Cx45 and Cx36 in apposing hemiplaques of truly heterotypic gap junctions would precisely overlap and could not be separately resolved by confocal microscopy because of the molecular dimensions of apposed connexons versus the $\sim 0.2 \mu \mathrm{m}$ limit of resolution of light microscopy. To test whether published images showing "adjacent" puncta for Cx36 and $\mathrm{Cx} 45$ are consistent with close association of separate $\mathrm{Cx} 36-$ homotypic and $\mathrm{Cx} 45+\mathrm{Cx} 36$ bihomotypic gap junctions at triadic appositions of cone bipolar cells with AII amacrine cells [Kolb (1979), her Fig. 29b], and to assess the probability of coincidental association of puncta (Han and Massey, 2005; Dedek et al., 2006), images of Cx36-fluorescent puncta were flipped horizontally in fields double labeled for $\mathrm{Cx} 45$ and $\mathrm{Cx} 36$ (Fig. $2 \mathrm{~B}$, comparing the same set of images as in Fig. $2 A$ ). With the flipped image of Figure $2 B 2$, there was rarely total overlap of individual green and red puncta (Fig. 2 B3), compared with nearly total overlap in nonflipped images. Cx45-positive puncta exhibiting an estimated greater than half area of overlap versus less than half area overlap
Table 3. Numbers of gap junctions labeled for $\mathrm{C} \times 36, \mathrm{C} x 45$, or $\mathrm{C} \times 36+\mathrm{C} \times 45$ in FRIL single-replicas of mouse and rat retinas that were double labeled for $\mathrm{C} x 36$ plus Cx45

\begin{tabular}{lcllll}
\hline & Mouse & & & Rat \\
\cline { 2 - 3 } Antibody & Shorter labeling $^{a}$ & Longer labeling $^{b}$ & & Shorter labeling & Total \\
\hline Cx36 & $408(92 \%)$ & $137(88 \%)$ & & $62(85 \%)$ & $607(90 \%)$ \\
Cx36+Cx45 & $29(7 \%)$ & $19(12 \%)$ & & $10(14 \%)$ & $58(9 \%)$ \\
Cx45 & $5(1 \%)$ & $0(0 \%)$ & & $1(1 \%)$ & $6(1 \%)$ \\
Total & $442(100 \%)$ & $156(100 \%)$ & $73(100 \%)$ & $671(100 \%)$ \\
\hline
\end{tabular}

Numbers in parentheses indicate percentage of labeled gap junctions found in each labeling protocol. These data do not include the 160-plus Cx36 and Cx36 + Cx45-containing gap junctions found in the double replicas (see Table 4). ${ }^{a}$ Shorter labeling was defined as $1-4.4 \mathrm{~h}$ for primary and $12-17 \mathrm{~h}$ for secondary antibody labeling; no significant differences were noted between $1-1.2 \mathrm{~h}$ and $4.4 \mathrm{~h}$ for primary antibodies.

${ }^{b}$ Longer labeling was defined as $5.3-6.8 \mathrm{~h}$ for primary and $21.5 \mathrm{~h}$ for secondary antibodies.

with Cx36-positive puncta represented 5.4\% $(n=5$; SEM $=$ $0.4 \%)$ versus $2.8 \%(n=5 ;$ SEM $=0.2 \%)$, respectively, compared with $87 \%$ colocalization in the nonflipped images. This indicates that $\mathrm{Cx} 45 / \mathrm{Cx} 36$ colocalization was not simply a consequence of the high density and large size of Cx36 puncta in the IPL.

To confirm that monoclonal and polyclonal anti-Cx36 antibodies generated against different sequences in $\mathrm{Cx} 36$ produced the same level of $\mathrm{Cx} 36$ detection, rather than potentially differential levels of labeling, thereby affecting the outcome of Cx36/ Cx45 colocalization counts when using these different antibodies, sections were double labeled for $\mathrm{Cx} 36$ with monoclonal anti$\mathrm{Cx} 36$ combined with polyclonal anti-Cx36. This combination of two anti-Cx36 antibodies showed nearly total overlap of red and green Cx36-immunopositive puncta (Fig. 2C). Similarly, we tested whether the widely used monoclonal anti-Cx45 antibody from Millipore Bioscience Research Reagents and the newly generated polyclonal anti-Cx45 antibody recognized the same or partially distinct subsets of Cx45-puncta in the IPL. Double labeling with these antibodies also showed nearly total overlap of immunopositive puncta (Fig. 2D).

\section{FRIL analysis of $\mathrm{Cx} 45$ colocalization with $\mathrm{Cx} 36$}

In samples double labeled for $\mathrm{Cx} 36+\mathrm{Cx} 45$, gap junctions containing $\mathrm{Cx} 45$ were found in both OFF and ON sublaminae of the IPL. In addition, a few double-labeled gap junctions were found in the outer plexiform layer (data not shown). In 24 FRIL replicas (21 replicas from mice and 3 from rats) that had been double labeled for $\mathrm{Cx} 36+\mathrm{Cx} 45$, a large " $N$ " of 671 immunogold-labeled gap junctions were detected (599 in mouse and 73 in rat; Table 3 ). Of these, $91 \%$ (545 of 599) in mouse IPL and 85\% (62 of 73) in rat IPL were labeled for Cx36 only (Fig. 3A2), 8\% (48 of 599) and $14 \%$ ( 10 of 73 ) in mouse and rat, respectively, were double labeled for both Cx36 and Cx45 (Fig. 3A1, B, C), and 1\% (6 of 599) and $1.4 \%$ ( 1 of 73 ) of those in mouse and rat, respectively, were labeled for Cx45 only (Fig. 3D). Approximately 44\% (28 of 64) of Cx45-containing gap junctions were "miniature" gap junctions [i.e., contained < 100 connexons; defined by Rash et al. (2007b); see also Rash et al. (1996)], whereas 50\% (32 of 64) contained between 100 and 400 connexons $(0.1-0.2 \mu \mathrm{m}$ in diameter; defined as "medium-size"), and 6\% (4 of 64) contained between 400 and 2200 connexons $(0.2-0.5 \mu \mathrm{m}$ in diameter; defined as "large"). Overall, 91\% (48 of 53) of Cx45-containing gap junctions in mouse IPL were colabeled for Cx36. Double-labeled "mini" gap junctions and those larger gap junctions in which one or the other connexin is present in low amounts (i.e., $<30$ connexons) may be difficult to detect by FRIL or by conventional immunofluorescence imaging (Kamasawa et al., 2006), regard- 


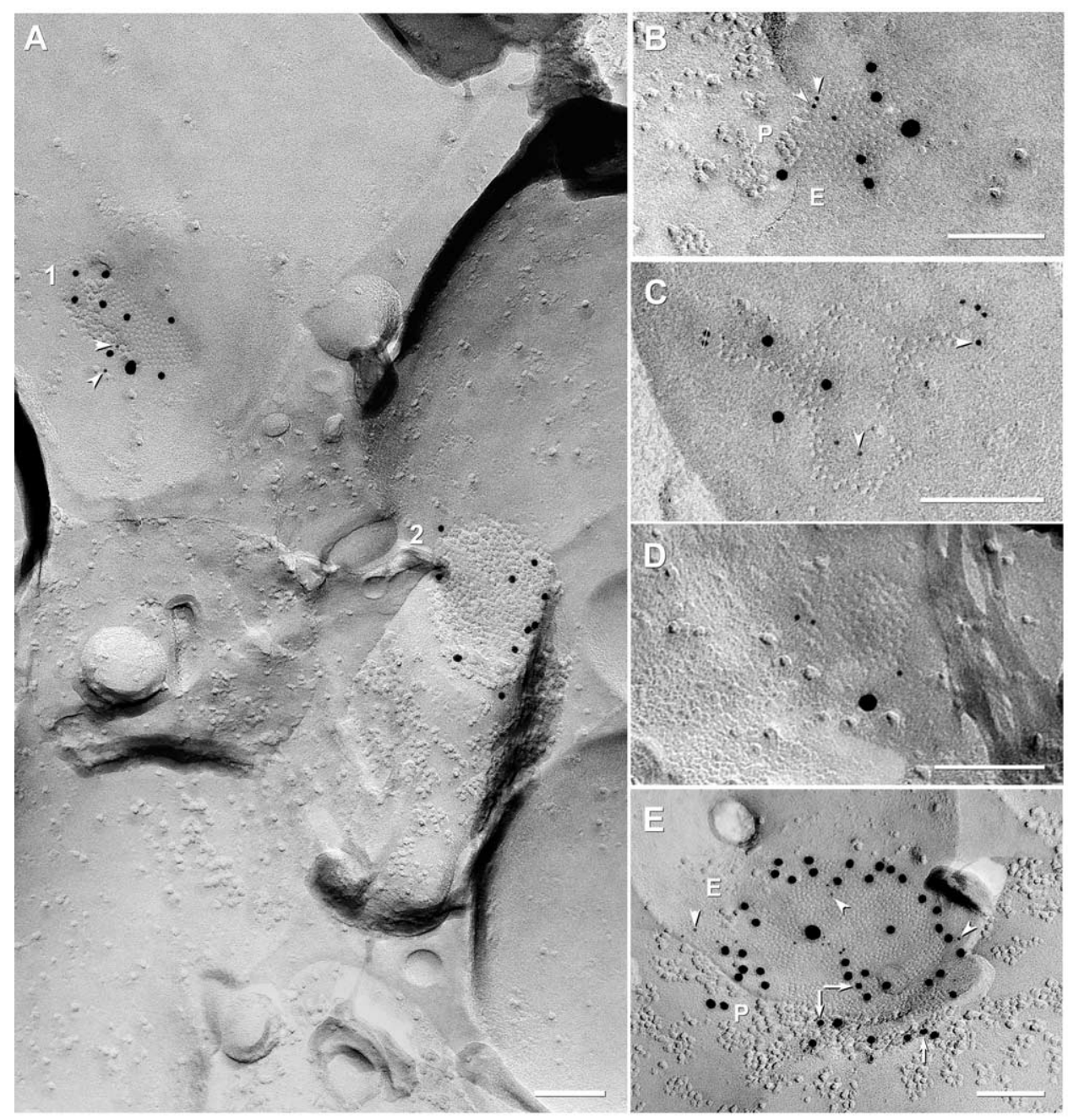

Figure 3. FRIL localization of $\mathrm{C} \times 45$ versus $\mathrm{C} \times 36$ in mouse $(\boldsymbol{A}-\boldsymbol{D})$ and rat $(\boldsymbol{E})$ IPL. $\boldsymbol{A}$, Neuronal gap junctions in adjacent cells, one of which (1; 210 connexons) is labeled for both $(\mathrm{X} 45$ [one $18 \mathrm{~nm}$ gold and two $6 \mathrm{~nm}$ gold beads (arrowheads)] and (X36 ( 450 connexons; eight $12 \mathrm{~nm}$ gold beads), and the second of which (2) is labeled for $(x 36$ only (ten $12 \mathrm{~nm}$ gold beads). 1, 0verall LE $=1: 19$; 2, LE = 1:45. B, Medium-size plaque gap junction (139 connexons) labeled for ( $x 45$ [three $6 \mathrm{~nm}$ gold beads (arrowheads) and one $18 \mathrm{~nm}$ gold bead] and (X36 (five $12 \mathrm{~nm}$ gold beads); overall LE = 1:15. C, Medium-size reticular gap junction (106 connexons) labeled for $(x 45$ (six $6 \mathrm{~nm}$ gold beads; arrowheads) and for $(x 36$ (three $12 \mathrm{~nm}$ gold beads). Two gold beads (thin cross-bars) within the apparent "radius of uncertainty" for connexon labeling represent "false-positive" labeling (i.e., "noise") because stereoscopic analysis (data not shown) revealed that both were $>1 \mu \mathrm{m}$ above the replica on an unstable wisp of undissolved Lexan plastic. Overall LE $=1: 12$. D, Small gap junction (68 connexons) in rat IPL labeled for Cx45 only (one $18 \mathrm{~nm}$ and three $6 \mathrm{~nm}$ gold beads; zero $12 \mathrm{~nm}$ gold beads are present for $(\times 36)$. Cx45 LE $=1: 17$. This gap junction may be too small to allow positive analysis regarding (x36. $\boldsymbol{A}$ and $\boldsymbol{C}$ are from same replica. $\boldsymbol{E}$, Large plaque gap junction (797 connexons) with small area of P-face and larger area of E-face, labeled for both Cx45 [three $12 \mathrm{~nm}$ gold beads (arrows) and one $30 \mathrm{~nm}$ gold bead] and for Cx36 [seventeen $6 \mathrm{~nm}$ gold beads (arrowheads) and forty-one $18 \mathrm{~nm}$ gold beads; labeled for approximately twice as long as all other FRIL images shown; see Materials and Methods for details]. Overall LE $=1: 13.5 \mathrm{Scale}$ bars, $0.1 \mu \mathrm{m}$.

less of the overall size of the gap junction, potentially leading to a slight underestimate of colocalization (tested next).

The ratio of the number of gold beads for $\mathrm{Cx} 45$ : $\mathrm{Cx} 36$ within individual $\mathrm{Cx} 45$-containing gap junctions varied from 6:1 (i.e., more $\mathrm{Cx} 45)$ to $1: 36$ (i.e., much more $\mathrm{Cx} 36$ ), with overall LEs ranging from $\mathrm{LE}=1: 3$ to $\mathrm{LE}=1: 59$ (i.e., from one gold bead per three connexons to one gold bead per 59 connexons). At the lower LE, some of the few examples of gap junctions containing $\mathrm{Cx} 45$ without $\mathrm{Cx} 36$ in samples labeled by our standard protocol $(<1 \%$ of total; 6 of 671$)$ may represent "false negatives" for Cx36.

As a test for a threshold of detection for FRIL based on LE $=$ 1:30 versus $\mathrm{LE}=1: 10$, three replicas were labeled for $5 \mathrm{~h}$ in primary antibodies and $21.5 \mathrm{~h}$ in secondary antibodies. In these replicas, 156 relatively heavily labeled gap junctions were found, $88 \%$ ( 137 of 156 ) of which were labeled for Cx36 only, 12\% ( 19 of 156) of which were colabeled for $\mathrm{Cx} 36+\mathrm{Cx} 45$ (Fig. 3E), and $0 \%$ of which ( 0 of 156) were labeled for Cx45 only, suggesting that very nearly $100 \%$ of Cx 45 -containing gap junction plaques also contain $\mathrm{Cx} 36$, and that no significant population of gap junctions contained only $\mathrm{Cx} 45$ without $\mathrm{Cx} 36$. The increased ratio of $\mathrm{Cx} 45$ containing to Cx36-containing gap junctions after longer labeling times is not attributable to increased nonspecific labeling because almost all of the largest plaque gap junctions (11 of 156) and the only large string gap junction encountered (1 of 156), where nonspecific labeling would be most apparent, were labeled only for $\mathrm{Cx} 36$ and not for $\mathrm{Cx} 45$. Interestingly, in heavily labeled samples (Fig. $3 E$ ), the gold beads were concentrated near the periphery of gap junctions, a distribution that is suggestive of steric hindrance of antibody access to the center of larger gap junctions (investigated further below).

\section{Morphological characteristics of $\mathrm{Cx} 45$-containing gap junctions}

We previously showed that in IPL, Cx36 was present in a wide variety of morphological classes of gap junctions, designated as crystalline plaque, noncrystalline plaque, reticular, ribbon, and 


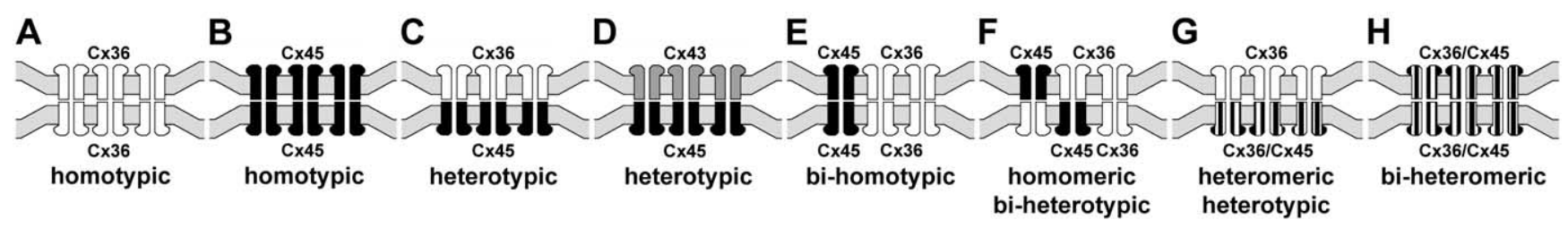

Figure 4. Eight generalized connexin/connexon configurations proposed to occur within neuronal gap junctions. $\boldsymbol{A}, \boldsymbol{B}$, Homomeric homotypic $\mathrm{Cx} 36$-to- $\mathrm{C} \times 36$ channels ( $\boldsymbol{A})$ and $\mathrm{Cx} 45$-to- $\mathrm{C} \times 45$ channels (B). C, Cx36 in the top cell and (X45 in the bottom cell, with Cx36 linking to Cx45 ("homomeric heterotypic"). D, Cx43 in the top cell and Cx45 in the bottom cell, with CX43 linking to CX45

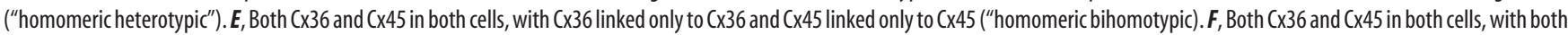
connexins on one side linked to both connexins on the other side ("homomeric biheterotypic"). G, (X36 only in the top cells linking to connexons containing a mixture of $(x 36 / C \times 45$ in the bottom cell (homomeric to heteromeric channels). $\boldsymbol{H}$, Each connexon contains both $\mathrm{Cx} 36$ and $\mathrm{Cx} 45$ (heteromeric connexons), linking to heteromeric connexons in the other cell (heteromeric to heteromeric channels).

string configurations, with string gap junctions associated with more abundant ZO-2 labeling and plaque gap junctions associated with more abundant ZO-1 labeling (Ciolofan et al., 2006; Kamasawa et al., 2006). Ribbon and string configurations represented $\sim 50 \%$ of $\mathrm{Cx} 36$-containing gap junctions in the OFF sublamina. In contrast, almost all (94\%; 60 of 64) Cx45-containing gap junctions in this study were plaques (Fig. $3 A-C$ ), and several $(6 \% ; 4$ of 64$)$ were reticular gap junctions (i.e., plaques with internal voids) (Fig. $3 D)$, but none (0\%; 0 of 64$)$ were string or ribbon gap junctions. These differences in morphology suggest that Cx45containing gap junctions may be associated with different scaffolding proteins than those containing only Cx36 (see below).

Absence of heterotypic $\mathrm{Cx} 36 / \mathrm{Cx} 45$ gap junctions in HeLa cells Teubner et al. (2000) reported that in HeLa cells separately expressing Cx36 and Cx45, "None of these co-cultures demonstrated transfer above background of either Neurobiotin or Lucifer yellow (data not shown)", and concluded that Cx45 does not form functional couplings with $\mathrm{Cx} 36$. To investigate conditions under which $\mathrm{Cx} 45$ and $\mathrm{Cx} 36$ engage in gap junction plaque formation together and separately, we used HeLa cells expressing $\mathrm{Cx} 45$ and $\mathrm{Cx} 36$ to evaluate several potential connexin coupling combinations by immunofluorescence imaging, which was not done in the previous studies. In principal, a connexon hemichannel may assemble from six identical connexin monomers to form "homomeric" connexons (Fig. $4 A-F$ ) or assemble from two or more different connexins to form "heteromeric" connexons (Fig. $4 G, H)$. In turn, connexons may link to identical homomeric connexons to form "homotypic" channels (Fig. $4 A, B, E$ ), or they may link to connexons containing unlike connexins to form "heterotypic" channels (Fig. 4C,D,F). Because FRIL revealed that Cx45 was almost always accompanied by $\mathrm{Cx} 36$ within individual hemiplaques in retina (supporting one of Fig. $4 E-H$ ), we tested whether homomeric $\mathrm{Cx} 45$ hemichannels can form heterotypic plaques by coupling with homomeric Cx36 hemichannels (as in Fig. 4C). First, as a positive control for the ability of HeLa cells to form homomeric heterotypic junctional plaques consisting of Cx45-to-Cx43 channels (as in Fig. 4D), HeLa cells expressing Cx45 (Cx45-HeLa) were cocultured with cells stably expressing $\mathrm{Cx} 43$ (Cx43-HeLa). In mixtures of these cells grown to near confluence, double-immunofluorescence labeling showed that within colonies of cells expressing either one or the other connexin, they formed either Cx45-positive plaques (Fig. 5A1) or $\mathrm{Cx} 43$-positive plaques (Fig. 5A2) at apposing cell membranes. At locations where $\mathrm{Cx} 45$ colonies abutted $\mathrm{Cx} 43$ colonies, Cx45immunofluorescent puncta at cell appositions were colocalized with Cx43 (Fig. 5A3), suggesting that these connexins form homomeric heterotypic gap junctions (as in Fig. 4D), consistent with the permissiveness of these connexins to form functional gap junctions (Elfgang et al., 1995; Rackauskas et al., 2007). Second, in mixtures of HeLa cells stably expressing only Cx36 (Cx36$\mathrm{HeLa}$ ) cocultured with cells stably expressing only $\mathrm{Cx} 45$, colonies of cells expressing either $\mathrm{Cx} 45$ or $\mathrm{Cx} 36$ were found to display large numbers of $\mathrm{Cx} 45$-puncta (Fig. 5B1) or Cx36-puncta (Fig. $5 B 2$ ) within their respective colony compartments. At abutments of these homotypically expressing cells, there was a total absence of $\mathrm{Cx} 45 / \mathrm{Cx} 36$ colocalization (Fig. 5B3), and this was consistent throughout the coculture, indicating failure of gap junction plaque formation between $\mathrm{Cx} 45-\mathrm{HeLa}$ and Cx36-HeLa cells. This shows that in HeLa cells, homomeric Cx36 does not form heterotypic channels with homomeric $\mathrm{Cx} 45$ (i.e., inability to form configuration shown in Fig. 4C). Similar results were obtained whether we used $\mathrm{Cx} 45$-HeLa cells provided to us by K. Willecke or those generated as described in Materials and Methods. Based on the ability of $\mathrm{Cx} 45$ - and Cx43-expressing HeLa cells to form heterotypic gap junctions (Fig. 5A3), this failure to form heterotypic Cx36-to-Cx45 gap junctions in the same cells that separately form homotypic gap junctions cannot be caused by an internal deficiency of connexin sorting, transport, or connexin interaction with scaffolding proteins. Consequently, the possibility of $\mathrm{Cx} 45 / \mathrm{Cx} 36$ heterotypic coupling was investigated further.

After transient transfection of Cx36-HeLa cells with $\mathrm{Cx} 45$, adjacent pairs of cells expressing both of these connexins displayed $\mathrm{Cx} 45 / \mathrm{Cx} 36$ colocalization at points of plasma membrane apposition (Fig. 5C), indicating the ability of HeLa cells to traffic the coexpressed connexins to the same membrane locations, apparently to the same gap junctional plaques, as occurs in retina. Also encountered were pairs of adjacent Cx36-HeLa cells that were each transiently transfected with $\mathrm{Cx} 45$ and that formed Cx36/Cx45 colocalized plaques at points of contact with each other; however, where $\mathrm{Cx} 45 / \mathrm{Cx} 36$ cells contacted adjacent cells expressing only Cx36, they displayed only Cx36-containing plaques (Fig. 5D). This shows that Cx45 connexons do not simply undergo cotrafficking with $\mathrm{Cx} 36$ connexons to plasma membranes, but rather require $\mathrm{Cx} 45$-containing connexons in the adjacent cell to achieve stable plasma membrane localization. These observations also indicate that $\mathrm{Cx} 45$ coexpressed with $\mathrm{Cx} 36$ does not form heteromeric connexons in one cell that couple with homomeric Cx36 connexons in the other cell, but that when Cx45 is coexpressed in Cx36-expressing HeLa cells, they form bihomotypic plaques (i.e., as in Fig. $4 E$ ). However, because neither single-replica FRIL nor immunofluorescence imaging have sufficient resolving power, these experiments do not eliminate the possibility that $\mathrm{Cx} 36$ and $\mathrm{Cx} 45$ may form individual heteromeric connexons that stably couple to either heteromeric or homomeric connexons in apposing cells (as in Fig. 4G,H), but this is considered unlikely because $\mathrm{Cx} 36$ and $\mathrm{Cx} 45$ are in different connexin classes (Söhl and Willecke, 2003) that are proposed to be 
incapable of forming heteromeric connexins (Evans and Martin, 2002). Nevertheless, the arrangement of homomeric versus heteromeric connexons might be ascertained by double-replica FRIL if labeling for the two connexins were to be unequivocally segregated (examined in next section).

\section{Double-replica analysis of $\mathrm{Cx} 45$ and} $\mathrm{Cx} 36$ in apposed hemiplaques in rat IPL Because conventional FRIL is based on random fracturing through complex tissue, a sufficiently large sample size will reveal all possible configurations of gap junctions and accurately reveal the range of connexon labeling and connexin pairing relationships. The absence of a significant population of gap junction plaques containing only $\mathrm{Cx} 45$ ( $0.6 \%$, all data combined) means that there is no significant population of gap junctions containing only Cx45 in only one hemiplaque or in both apposed hemiplaques. Only by the use of double replicas showing both sides of the same gap junction could it be proven that both connexins are contained in both sides of a pair of hemiplaques. Moreover, the above immunofluorescence results documenting gap junction plaque-forming capability of Cx45 and Cx36 in HeLa cell expression systems underscored the necessity for examining matched double replicas of $\mathrm{Cx} 45$-containing gap junctions in retina.

In both single and double replicas, the fracture plane always separates apposed connexons at their point of contact in the extracellular space (Fig. 6A) [as previously shown (Fujimoto, 1997; Rash and Yasumura, 1999; Nagy et al., 2004)], separating gap junctions into two complementary hemiplaques, each containing connexons from only one or the other cell (Fig. 6B, C). Immunogold labeling of cytoplasmic epitopes of connexons occurs in the residual cytoplasm beneath the $\mathrm{Pt} / \mathrm{C}$ replica (Fig. 6B, C). Moreover, labeling is approximately equal beneath both E-face pits and $\mathrm{P}$-face particles, demonstrating that the connexons of the subjacent cell are retained and not washed away during SDS cleaning (Fujimoto, 1997; Rash and Yasumura, 1999). In the case of double replicas, how-

ever, both fracture faces are retained and replicated, and both sides are approximately equally well labeled in the matching complementary images of both E-face pits and P-face IMPs (Fig. $6 B-G$ ). This feature for clean separation of hemiplaques in vertebrate gap junctions allows definitive assignment of one or multiple connexins to individual hemiplaques belonging to one or the other apposed cell (Rash et al., 2001, 2004; Nagy et al., 2004; Kamasawa et al., 2005), and equally important, potentially allows assessment of whether Cx45 and $\mathrm{Cx} 36$ are intermixed (as heteromeric connexons) (Fig. 4G,H) or segregated into domains of homomeric connexons (Fig. $4 E$ ).

In double replicas of complex neuropil, multiple structural
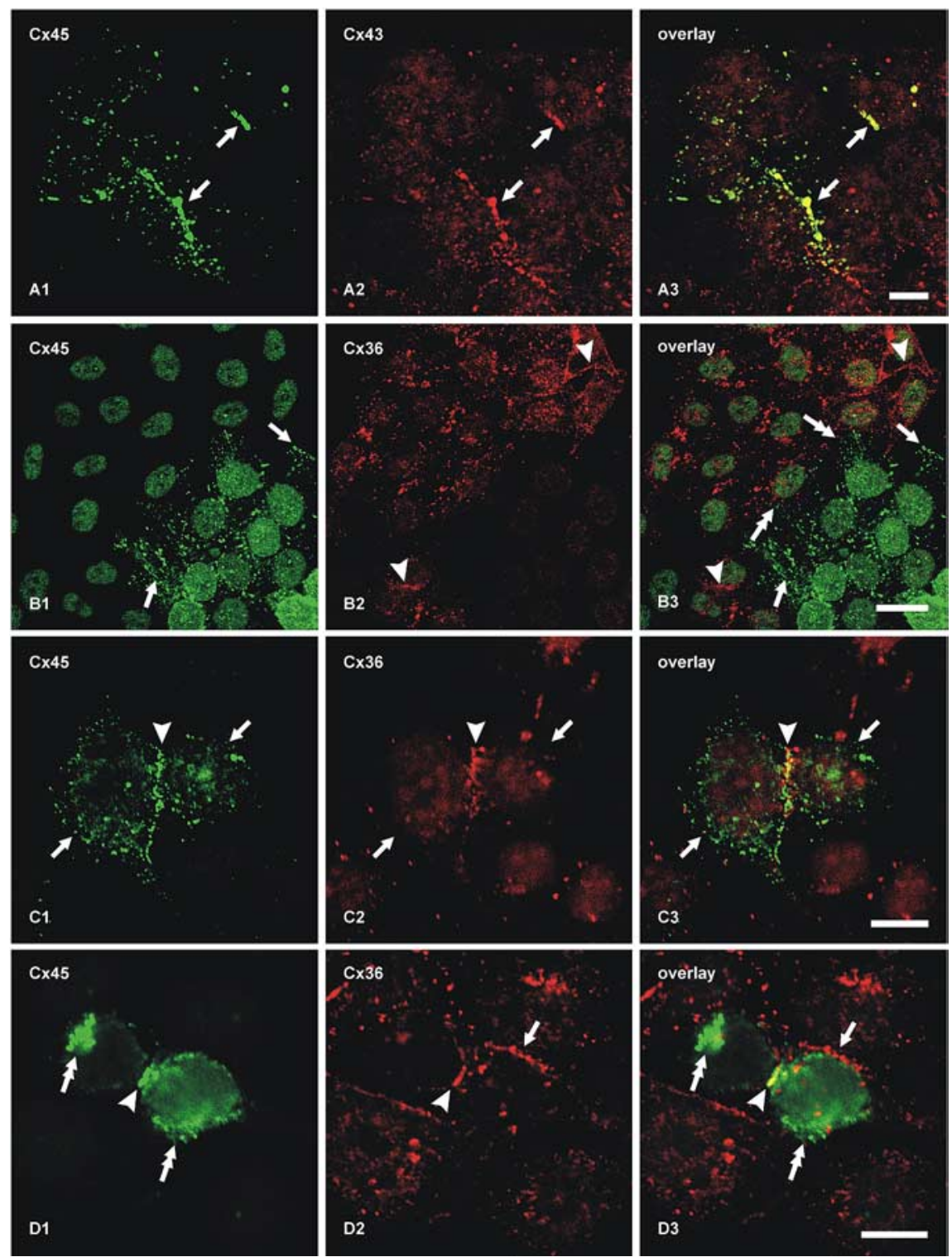

Figure 5. Double-immunofluorescence labeling of connexins in cultures containing mixtures of HeLa cells expressing $C \times 45$, Cx43, or Cx36. A, Coculture of cells stably expressing Cx45 with those expressing Cx43, showing colocalization of Cx45/Cx43 a with those expressing $\mathrm{C} \times 36$, showing $\mathrm{C}$ 45-positive puncta at cell appositions among colonies of $\mathrm{C}$ 45-HeLa cells (B1, bottom right half of field and arrows) and (x36-positive puncta at appositions among (x36-HeLa cells (B2, top left half of field and arrowheads). There is a lack of Cx45/Cx36 colocalization at abutments between Cx45-HeLa and Cx36 HeLa cells (B3, doubleheaded arrows). C, HeLa cells stably expressing Cx36 and transiently transfected with Cx45, showing two apposed cells (arrows)

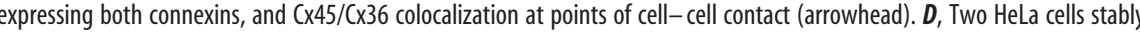
expressing Cx36 and transiently transfected with Cx45, showing Cx45 localized intracellularly (D1, double-headed arrows), Cx36/Cx45 colocalization at points of cell-cell contact between cells expressing both connexins (arrowhead), and absence of Cx45 at points at which double-expressing cells make contacts with cells expressing only Cx36 (arrow). Scale bars, $10 \mu \mathrm{m}$.

markers are used to find the same gap junction in both complementary replicas. However, corresponding areas in one or the other replica are often missing because (1) one or the other may be covered by grid bars, even when using thin-bar slot grids (Fig. $6 D, D^{\prime}$; dotted lines on each sample correspond to locations of obscuring grid bars in the complementary replica); (2) fragmentation and loss of complementary areas may occur during sample processing (Fig. 6D, $D^{\prime}$; outlines indicate portions lost in its complementary replica); or (3) one or the other matching area was obscured by adhering debris (one example, not shown). Nevertheless, in a large portion of one set of matched double replicas 
A

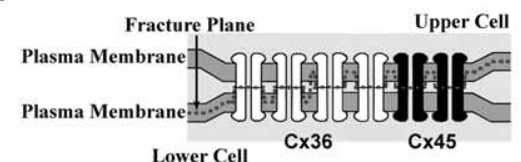

B

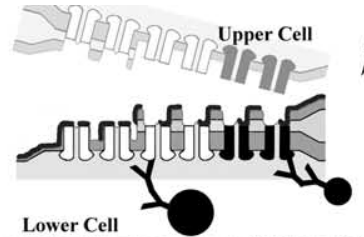

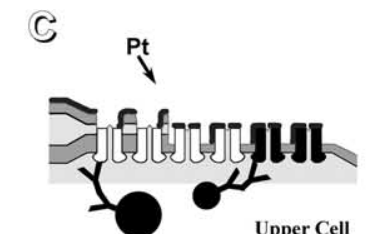
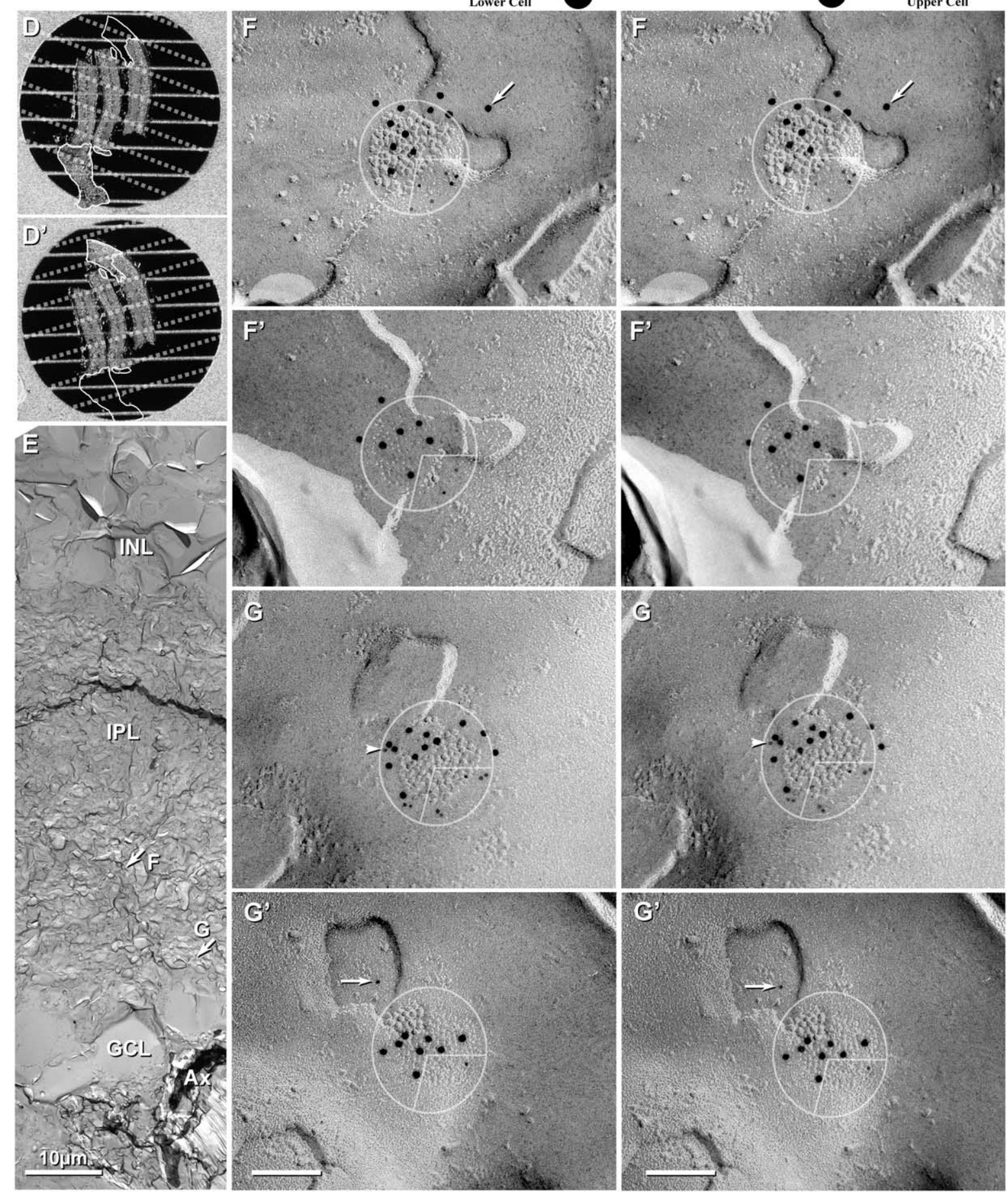

Figure 6. Images and the interpretation of labeling in matched double replicas. A-C, Scale diagrams showing gap junction before and after freeze fracturing and retrieval of complementary replicas. $A$, The fracture plane (dashed line) separates connexons at their points of contact in the extracellular space, leaving all connexons of the bottom cell for subsequent immunogold labeling. $B, C$, Creation of double replicas having complementarity of E- and P-fracture faces. Each matching replica contains connexons from only one cell, but the E-face of one cell and the P-face of the other cell. $\boldsymbol{D}, \boldsymbol{D}^{\prime}$, Images from dissecting microscope showing matched double replicas containing three strips of retina after SDS washing and immunogold labeling. $E$, Low-magnification image of one side of a complementary replica, with locations of two of the mapped gap junctions indicated by arrows. Ax, Axons. $\boldsymbol{F}, \boldsymbol{F}^{\prime}, \mathbf{G}, \boldsymbol{G}^{\prime}$, High-magnification stereoscopic views of complementary replicas of two gap junctions, with $10 \mathrm{~nm}$ gold labeling $\mathrm{X} \times 36$ and $5 \mathrm{~nm}$ gold labeling $C \times 45$. $C \times 36$ labeling is present beneath three quadrants of both gap junctions (E-face pits in top replica and complementary $P$-face particles in bottom replica). In the bottom right quadrant, $5 \mathrm{~nm}$ (x45 labels are present. Initial precoating with $2-3 \mathrm{~nm}$ of carbon partially obscured E-face connexon pits. The arrow (in $\boldsymbol{F}$ ) indicates a gold bead beyond the $28 \mathrm{~nm}$ radius of immunogold labeling. The arrowhead (in $\mathbf{G}^{\prime}$ ) indicates a $5 \mathrm{~nm}$ gold label for $(x 45$, with possible corresponding label in the complementary image (G, arrow). Scale bars, $0.1 \mu \mathrm{m}$ unless otherwise indicated. 

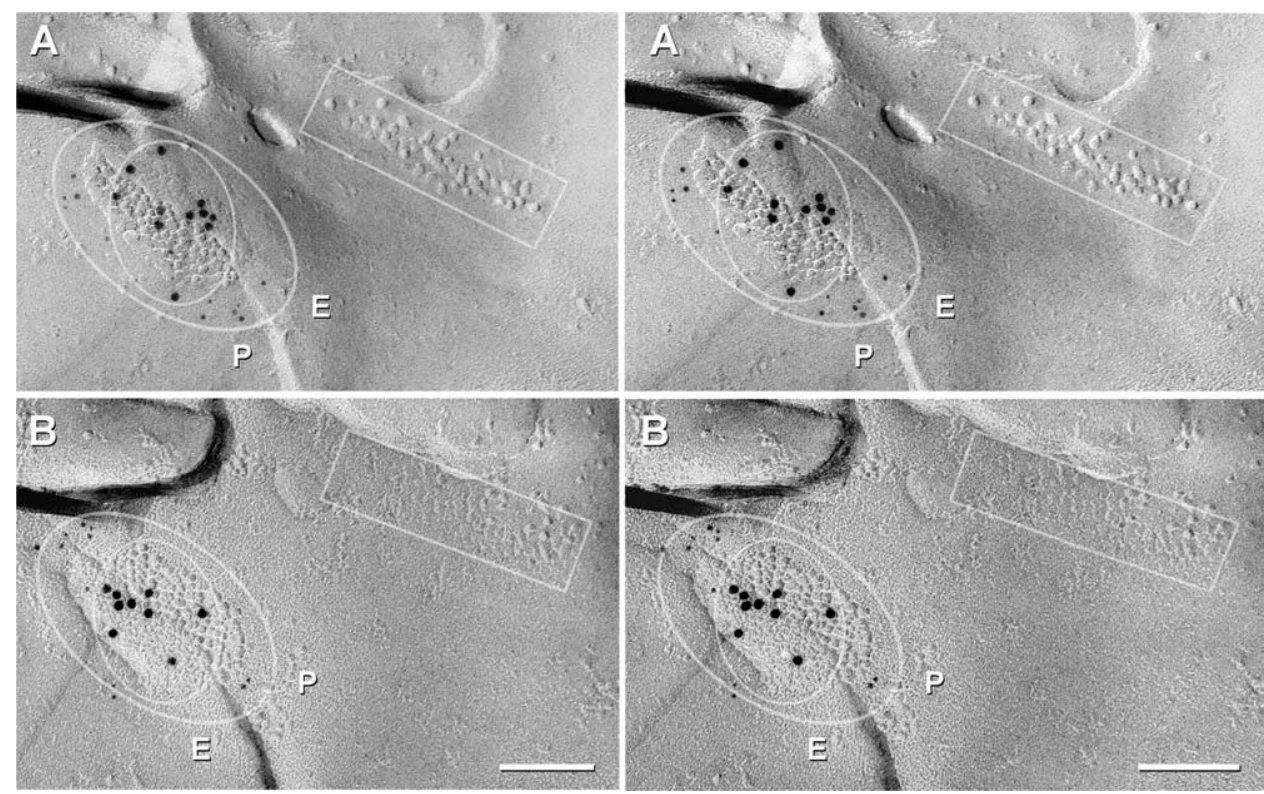

Figure 7. $\quad(x 45 / C \times 36$ double-labeled gap junction adjacent to a ribbon of E-face particles/P-face pits (rectangles) that are found postsynaptic to ribbon synapses, which in IPL, are characteristic of rod and cone bipolar cells. The outer oval delineates the area with increased ( $x 45$ labeling (twelve and eleven $5 \mathrm{~nm}$ gold beads, $\boldsymbol{A}$ vs $\boldsymbol{B}$ ), and the inner oval delineates the domain of $(\mathrm{X} 36$ labeling (eleven and nine $10 \mathrm{~nm}$ gold beads, $\boldsymbol{A}$ vs $\boldsymbol{B}$ ). P, P-face; E, E-face. Scale bars, $0.1 \mu \mathrm{m}$.

(Fig. $6 D, D^{\prime}$ ), we found $>160$ immunogold-labeled gap junctions, including $11 \mathrm{Cx} 45$-containing gap junctions that had matching complements, five of which are illustrated here (Figs. 6, 7; supplemental Fig. S1, available at www.jneurosci.org as supplemental material). Eight of these 11 pairs were labeled for both $\mathrm{Cx} 45$ and $\mathrm{Cx} 36$ in both matching hemiplaques. In these matched pairs, the number of gold beads for the two connexins was substantially greater in one versus the other hemiplaque in six pairs (Fig. 6F, G; supplemental Fig. S1 A, available at www.jneurosci.org as supplemental material), and approximately equal in two paired hemiplaques (Fig. 7). In six of eight pairs, Cx45 and Cx36 appeared to be segregated into domains, with labels for both connexins beneath their respective complementary sectors in the mirror hemiplaques (i.e., $\mathrm{Cx} 45$ opposite $\mathrm{Cx} 45$ and $\mathrm{Cx} 36$ opposite Cx36) (Figs. 6F, G, 7). This observed segregation of labels implies that the connexons are present in homomeric connexons that are further segregated into domains containing either $\mathrm{Cx} 36$ or $\mathrm{Cx} 45$ but not both (i.e., correspond to Fig. $4 \mathrm{E}$ but not to Fig. $4 \mathrm{G}$ or $4 H$ ). Variations in number of labels for each connexin in matched pairs are attributed to stochastic differences arising from the numerically low labeling efficiency ( $\mathrm{LE}=1: 15$ to $1: 20$ ) in these matched pairs versus the relatively few connexons of each connexin type, particularly in smaller gap junctions. Minor discrepancies in positions of gold beads (Fig. 6G, arrows) are attributed to the $28 \mathrm{~nm}$ "radius of uncertainty" of immunogold labeling (Fig. $6 B, C$ ) or to the displacement of connexons into lipid "blebs" formed during SDS washing (Rash and Yasumura, 1999; Kamasawa et al., 2006). These few examples of apparent segregation of each connexin into discrete domains do not eliminate the possibility that homomeric homotypic Cx45- and Cx36connexons may also be intermixed in some gap junctions. However, the relatively low labeling efficiency could not preclude the existence of a few heteromeric connexons. Nevertheless, our immunocytochemical data showing absence of $\mathrm{Cx} 45 / \mathrm{Cx} 36$ heterotypic coupling (Fig. 5), plus FRIL data in which 60 of 64 (and 19 of 19; Table 3) Cx45-labeled gap junctions also contained Cx36, combined with data from six of eight mirrored gap junctions showing approximate alignment of Cx45- versus Cx36containing domains, unequivocally document that $\mathrm{Cx} 45$ and $\mathrm{Cx} 36$ are present, together on both sides of the same gap junction, presumably with homomeric $\mathrm{Cx} 45$ connexons coupling with homomeric Cx45 connexons, and homomeric Cx36 connexons coupling with homomeric Cx36 connexons. This bihomotypic coupling pattern occurred in most if not all Cx45-containing gap junctions in mouse and rat IPL.

In three of the eight mirror pairs from the ON sublamina of IPL, double-labeled gap junctions were adjacent to linear arrays of postsynaptic E-face particles characteristic of ribbon synapses (Fig. 7, inscribed box), which in IPL, occur only in cells postsynaptic to rod and cone bipolar cells (Kolb, 1979). In each of these three mirror pairs, the cell that was postsynaptic to the ribbon synapse was linked to an unidentified third cell by a gap junction containing both $\mathrm{Cx} 45$ and $\mathrm{Cx} 36$ in both sides (inscribed ovals). Thus, these coupled cell pairs that were postsynaptic to bipolar cells in the ON sublamina coexpressed and cotargeted Cx45 and Cx36.

Of the remaining three gap junction pairs with unequal labeling of apposed hemiplaques (from 11 total), one small gap junction (37 connexons) was labeled for both Cx36 (seven gold beads) and $\mathrm{Cx} 45$ (two gold beads) on one side but was not labeled for either connexin on its matched complement (not shown). Assuming that the gap junction contained no more than $\sim 10 \mathrm{Cx} 45$ connexons and $27 \mathrm{Cx} 36$ connexons, and nominal $\mathrm{LE}=1: 20$, the complete absence of labeling for either connexin on the unlabeled side would be consistent with normal stochastic variability of labeling. The second asymmetrically labeled gap junction $(\sim 100$ connexons) had three gold beads for $\mathrm{Cx} 45$ and seven gold beads for $\mathrm{Cx} 36$ on one side and zero gold beads for $\mathrm{Cx} 45$ and five gold beads for $\mathrm{Cx} 36$ on the complementary surface. The third of three unequally labeled pairs was a large gap junction $(>400$ connexons) that was well labeled for Cx36 in both the upper and lower hemiplaques (37 and 32 gold beads, respectively) (supplemental Fig. S1 $B$, available at www.jneurosci.org as supplemental material) but contained only a single gold bead for Cx45 on one side 
and none on the other side. The latter pair of images could imply that there were equally few $\mathrm{Cx} 45$ connexons in the mirror hemiplaque, or it could imply the presence of a few unpaired Cx45 connexons. However, this discrepancy of one versus zero gold beads for $\mathrm{Cx} 45$ is also consistent with normal stochastic differences in connexin labeling efficiency.

\section{Statistical analysis of $\mathrm{Cx} 45$ relationships with $\mathrm{Cx} 36$ in retinal neurons and gap junctions}

To test various hypotheses regarding expression and localization of Cx36 and Cx45 in the retina, we used a web-based on-line statistical analysis system to calculate confidence intervals (http://www.measuringusability.com/wald.htm) (as described in Hypothesis 3).

Hypothesis 1: Cx45 and CX36 are separately expressed in a neuron subtype-specific manner

The hypothesis that $\mathrm{Cx} 45$ is not coexpressed in cells that express Cx36 is nullified by finding in single replicas that most (60 of 64) Cx45-containing gap junctions also had Cx36 labeling (Table 3), and further nullified by 19 of 22 mirror hemiplaques in double replicas showing that both connexins occur in the same cell (Figs. $6,7)$. However, the four of 64 examples of $\mathrm{Cx} 45$ labeling without Cx36 labeling are consistent with one of the following: (1) incomplete (i.e., false-negative) labeling for Cx36 in a very small fraction (4 of 64) of Cx45 expressing cells, (2) lack of simultaneous insertion of $\mathrm{Cx} 36$ with $\mathrm{Cx} 45$ into plaques [whereas endocytotic retrieval of connexons involves internalization of structurally coupled membrane patches (Gaietta et al., 2002)], or (3) existence of a small fraction of $\mathrm{Cx} 45$-expressing cells that do not coexpress Cx36. In the latter case, Hypothesis 1 might still apply, but at most, only to a very small fraction of Cx45-expressing cells.

Hypothesis 2: Cx45-expressing cells have hemiplaques containing only Cx45, either as monohomotypic (Cx45-to-Cx45) or heterotypic (Cx45-to-Cx36) gap junctions

Hypothesis 2 is invalidated by the demonstration in single replicas that $>90 \%$ (60 of 64 ) of Cx45-containing hemiplaques also contain Cx36 (Fig. 3, Table 3). Similarly, double replicas showed that none of 11 matched pairs of $\mathrm{Cx} 45$-containing gap junctions had only Cx45 in either of their apposed hemiplaques (Figs. 6, 7; supplemental Fig. S1, available at www.jneurosci.org as supplemental material), further invalidating Hypothesis 2.

Hypothesis 3: Cx36 is present in Cx45-containing gap junctions, forming bihomotypic plaques

Table 4 presents the percentages, along with 95\% confidence intervals, for $\mathrm{Cx} 45+\mathrm{Cx} 36$ forming bihomotypic gap junctions in mouse and rat IPL in both single replicas and double replicas, where 93.8 to $100 \%$ of $\mathrm{Cx} 45$-containing gap junctions also contain Cx36. Moreover, eight of 11 pairs of Cx45-containing gap junctions found in double replicas contained both $\mathrm{Cx} 45$ and Cx36 in both sides, with six of those pairs, to the limit of the radius of uncertainty of immunogold labeling, having nearprecise mirror distributions of labels for both connexins, thereby demonstrating the presence of bihomotypic gap junctions that also are primarily or exclusively homomeric.

\section{$\mathrm{Cx} 45$ in relation to $\mathrm{ZO}-1, \mathrm{ZO}-2$, and $\mathrm{ZONAB}$ in retina}

To further characterize the basis for Cx45 occurrence almost exclusively in plaque but not string gap junctions, we investigated possible differences in their coassociated cytoplasmic scaffolding and accessory proteins. We previously documented a high degree of colocalization of $\mathrm{Cx} 36$ with the cytoplasmic proteins $\mathrm{ZO}-1$,
Table 4. Numbers of gap junctions in single and double replicas, percentage of $\mathrm{Cx} 45+\mathrm{C} \times 36$ double-labeled gap junctions, and lower and upper confidence intervals at $95 \%$ confidence levels for $\mathrm{Cx} 45$-containing gap junctions expressing both connexins

\begin{tabular}{lccc}
\hline Observed & Percentage & Lower 95\% Cl & Upper 95\% Cl \\
\hline $19 / 19^{a}$ & $100.00 \%$ & $85.4 \%$ & $100.0 \%$ \\
$41 / 45^{b}$ & $91.1 \%$ & $78.8 \%$ & $97.0 \%$ \\
$60 / 64^{c}$ & $93.8 \%$ & $84.8 \%$ & $98.3 \%$ \\
$20 / 22^{d}$ & $90.9 \%$ & $70.8 \%$ & $98.9 \%$ \\
$8 / 10^{e}$ & $80 \%$ & $44.4 \%$ & $97.5 \%$ \\
\hline
\end{tabular}

Cl, Confidence interval.

${ }^{a} \mathrm{C} 45+\mathrm{Cx} 36$-containing gap junctions from three FRIL replicas that were labeled for longer times in both primary and secondary antibodies.

${ }^{b} \mathrm{C} \times 45+C \times 36$-containing gap junctions from the other 15 FRIL replicas.

'C $x 45+$ Cx36-containing gap junctions, data combined from all 18 FRIL replicas.

${ }^{d} \mathrm{C} \times 45+\mathrm{C} \times 36$-containing gap junctions from 1 unpaired and 11 paired hemiplaques, calculated as individual hemiplaques, from one SDS-FRL double-replica.

${ }^{e} \mathrm{C} \times 45+$ Cx36-containing gap junctions from paired matched hemiplaques, calculated as pairs, from one SDS-FRL double-replica. (Not included is the pair with label for C 45 and Cx36 on one side and neither label on the other side.)

$\mathrm{ZO}-2$, and ZONAB in plaque, reticular, ribbon, and string gap junctions in mouse retina, as well as direct molecular interaction of Cx36 with ZO-1 (Li et al., 2004a; Ciolofan et al., 2006). Based on evidence provided above for Cx36 in most Cx45-containing plaque gap junctions, confocal double-immunofluorescence analysis was undertaken to determine whether $\mathrm{Cx} 45 / \mathrm{Cx} 36$ junctions are associated with each of the above accessory proteins or whether they represent a distinct subpopulation of $\mathrm{Cx} 36$ containing junctions lacking one or more of these scaffolding proteins. In vertical scans of retina presented as $z$-stack images of five scans, Cx45 was substantially colocalized with ZO-1 (Fig. $8 \mathrm{~A}$ ), as seen by presence of yellow puncta resulting from green/ red overlap. From counts of puncta in IPL of retinal sections that were double immunolabeled for $\mathrm{Cx} 45$ and $\mathrm{ZO}-1$, conducted using single confocal scans to avoid puncta overlap in the $z$-axis, $71 \%$ of $\mathrm{Cx} 45$-puncta were found to be colabeled and to exhibit total overlap with ZO-1 (Table 2). However, the vast majority of ZO-1-puncta were localized at structures other than Cx36- and Cx45-containing gap junctions, including adherens junctions of the outer limiting membrane (Ciolofan et al., 2006). After horizontal flipping of the ZO-1 image to form new overlay images (Fig. $8 B$ ), Cx45-positive puncta exhibiting an estimated greater than half area of overlap versus less than half area overlap with $\mathrm{ZO}$-1-positive puncta represented $11 \%(n=5$; SEM $=2 \%)$ versus $6.4 \%(n=5 ; \mathrm{SEM}=0.5 \%)$, respectively, compared with $71 \%$ in unflipped images. As observed for $\mathrm{Cx} 45$, the labeling density for ZO-2 was sparse, and little Cx45/ZO-2 colocalization was observed (7\%, Table 2) in all fields examined (Fig. 8C). Similarly, double labeling and counts of puncta in single confocal scans indicated negligible Cx45-puncta overlap with ZONAB-puncta (Table 2, Fig. 8D). In contrast, 39\% of Cx36-positive puncta contained $Z O N A B$, as described previously (Ciolofan et al., 2006). Thus, $\mathrm{ZO}-1$ but not $\mathrm{ZO}-2$ or $\mathrm{ZONAB}$ are present in and characteristic of $\mathrm{Cx} 45$-immunopositive puncta.

\section{$\mathrm{Cx} 45$ and ZO-1 in retina of $\mathrm{Cx} 36$ ko mice}

The presence of ZO- 1 at gap junctions containing $\mathrm{Cx} 45$ suggested its association either with $\mathrm{Cx} 45$ or exclusively with $\mathrm{Cx} 36$, which is also contained in most of these junctions and with which ZO-1 was recently found to be highly colocalized (Li et al., 2004a). This question was addressed by comparing labeling patterns of $\mathrm{Cx} 45$ in retina of wild-type and Cx36 ko mice. Double-immunofluorescence labeling was conducted to determine whether the presence of $\mathrm{Cx} 36$ at $\mathrm{Cx} 36 /$ Cx45 colocalized puncta was required for Cx45/ZO-1 association. 
As shown by image overlay (Fig. $8 E$ ), substantial Cx45/ZO-1 overlap was found in $\mathrm{Cx} 36$ ko mice. Counts of puncta revealed that $78 \pm 4.2 \%$ and $78 \pm$ $2.4 \%$ of $\mathrm{Cx} 45$-puncta were colocalized with ZO-1 in the IPL of retina from wildtype and $\mathrm{Cx} 36$ ko mice, respectively, which indicated that elimination of Cx36 had little affect on Cx45/ZO-1 association and suggested direct molecular interaction of Cx45 with ZO-1, as examined further, below. Confocal double immunofluorescence in vertical sections of retina from wild-type $\mathrm{C} 57 \mathrm{BL} / 6$ mice indicated similar labeling and distribution of $\mathrm{Cx} 36$ and $\mathrm{Cx} 45$ in the IPL (Fig. $8 F, G$ ) as observed in CD1 mice (Figs. 1, 2). Double-immunofluorescence imaging in retina of Cx36 ko mice showed an absence of labeling for Cx36 in the IPL (Fig. $8 \mathrm{H}$ ) and reduced labeling of $\mathrm{Cx} 45$ (Fig. 8I). Counts of Cx45-puncta in eight randomly selected fields in the IPL from wild-type and $\mathrm{Cx} 36$ ko mice revealed a significant $25 \%$ reduction $(p<$ $0.05)$ of $\mathrm{Cx} 45$-puncta in the ko mice.

\section{FRIL analysis of $\mathrm{Cx} 45$ colocalization with ZO-1}

SDS digestion (as used in SDS-FRL and FRIL) does not separate transmembrane proteins from many of their tightly bound cytoplasmic scaffolding and accessory proteins, leaving many of those molecules available for detection by immunogold labeling (Fujimoto, 1997; Fujimoto et al., 1997; Ciolofan et al., 2006). In a replica that was double labeled for Cx45 (Millipore Bioscience Research Reagents monoclonal antibody) plus ZO-1 (Invitrogen rabbit polyclonal antibody), 48 labeled gap junctions were found (Fig. 9). Of these, $44 \%$ (21 of 48 ) were double labeled for Cx45 plus ZO-1 (Fig. 9A,B), 4\% (2 of 48) were labeled for $\mathrm{Cx} 45$ only (data not shown), and $52 \%$ (25 of 48) were labeled for ZO-1 only (Fig. 9C,D), including five string gap junctions (Fig. 9C). In this replica, which was labeled relatively briefly $(1.25 \mathrm{~h}$ in primary antibodies and $16 \mathrm{~h}$ in secondary antibodies), 91\% (21 of 23) of Cx45-labeled gap junctions were colabeled for ZO-1. This means that ZO-1 is on both sides of most, if not all, $\mathrm{Cx} 45$-containing gap junctions. The remaining 25 gap junctions (52\%) were labeled for ZO-1 without Cx45, consistent with observations from immunofluorescence labeling (see above) and from FRIL (Ciolofan et al., 2006; Kamasawa et al., 2006) that many from the larger pool of homotypic Cx36-containing gap junctions also have closely bound ZO-1. With respect to ultrastructural correlates, almost all of those $\mathrm{ZO}$ $1 / \mathrm{Cx} 45$ double-labeled gap junctions were of the plaque type, and none were strings or ribbons. In contrast, 50\% of Cx36containing gap junctions in the OFF sublamina were string and ribbon configurations, and those were shown to be relatively de-
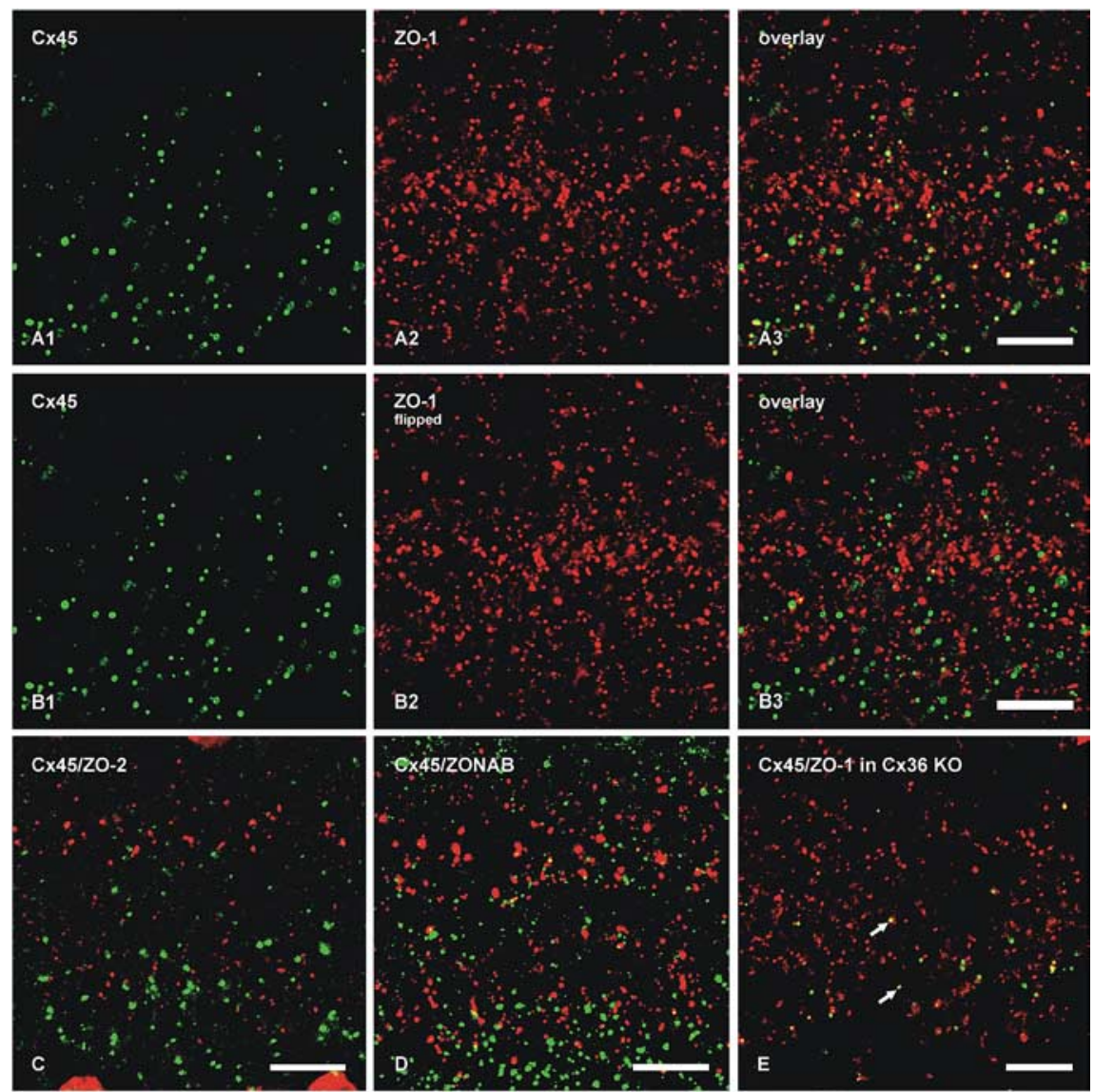

Cx45/ZO- 4 in $\mathrm{C} \times 36$ Ko
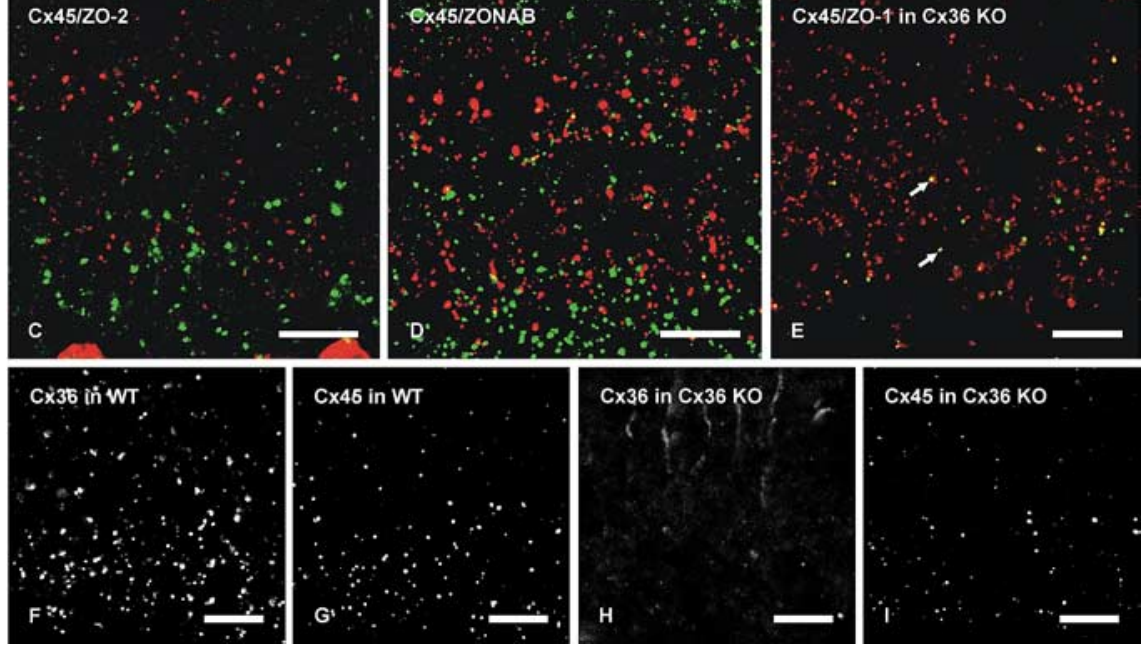

Figure 8. Laser-scanning confocal double immunofluorescence showing relationships of $\mathrm{Cx} 45$ with Z0-1, Z0-2, and ZONAB in the IPL of adult mouse retina, and $\mathrm{C} 336, \mathrm{C} \times 45$, and Z0-1 in the IPL of adult wild-type and $\mathrm{C} \times 36$ ko mice. Images show the IPL from puncta labeled for Z0-1. $\boldsymbol{B}$, The same set of laser-scanning confocal double-immunofluorescence images as in $\boldsymbol{A}$, showing minimal colocalization in the IPL after horizontal flipping of the image showing labeling for Z0-1. C, Doubleimmunofluorescence overlay showing lack of $\mathrm{C} 45$ (green) colocalization with ZO-2 (red). D, Double-immunofluorescence overlay showing very few $(x 45$-positive puncta (green) labeled for ZONAB (red). $E$, Double-immunofluorescence overlay showing the ce of $(x 45 / 20-1$ colocalization seen as yellow puncta (arrows) in the IPL of $(x 36$ ko retina. $F-I$, Confocal scans showing Cx36-puncta $(\boldsymbol{F})$ and $(x 45$-puncta $(\boldsymbol{G})$ in the IPL of wild-type retina and an absence of labeling for $\mathrm{C} \times 36(\boldsymbol{H})$ and a reduction of labeling for $\mathrm{C} \times 45(I)$ in IPL of $\mathrm{C} \times 36$ ko retina. Scale bars, $10 \mu \mathrm{m}$.

ficient in ZO-1 (Ciolofan et al., 2006; Kamasawa et al., 2006). For plaque gap junctions, $\mathrm{ZO}-1$ labeling was usually present across the gap junction plaques (Fig. $9 A, B$ ), whereas connexin labeling was often concentrated near the periphery (Figs. $3 A-C, 9 A, B$ ), possibly reflecting reduced penetration of anti-connexin antibodies into the gap junctional "cytoplasmic semi-dense matrix" (Sotelo and Korn, 1978; Kosaka and Kosaka, 2003) that is formed by ZO-1 and other scaffolding and accessory proteins (diagrammed in Fig. 9E). Given that IgG molecules are $\sim 8 \times 12 \times 12$ nm (Valentine and Green, 1967; Huber et al., 1976), or larger than the attached 6 or $10 \mathrm{~nm}$ gold beads, these cytoplasmic matrix proteins may also reduce immunofluorescence IgG labeling in strongly fixed sections. 

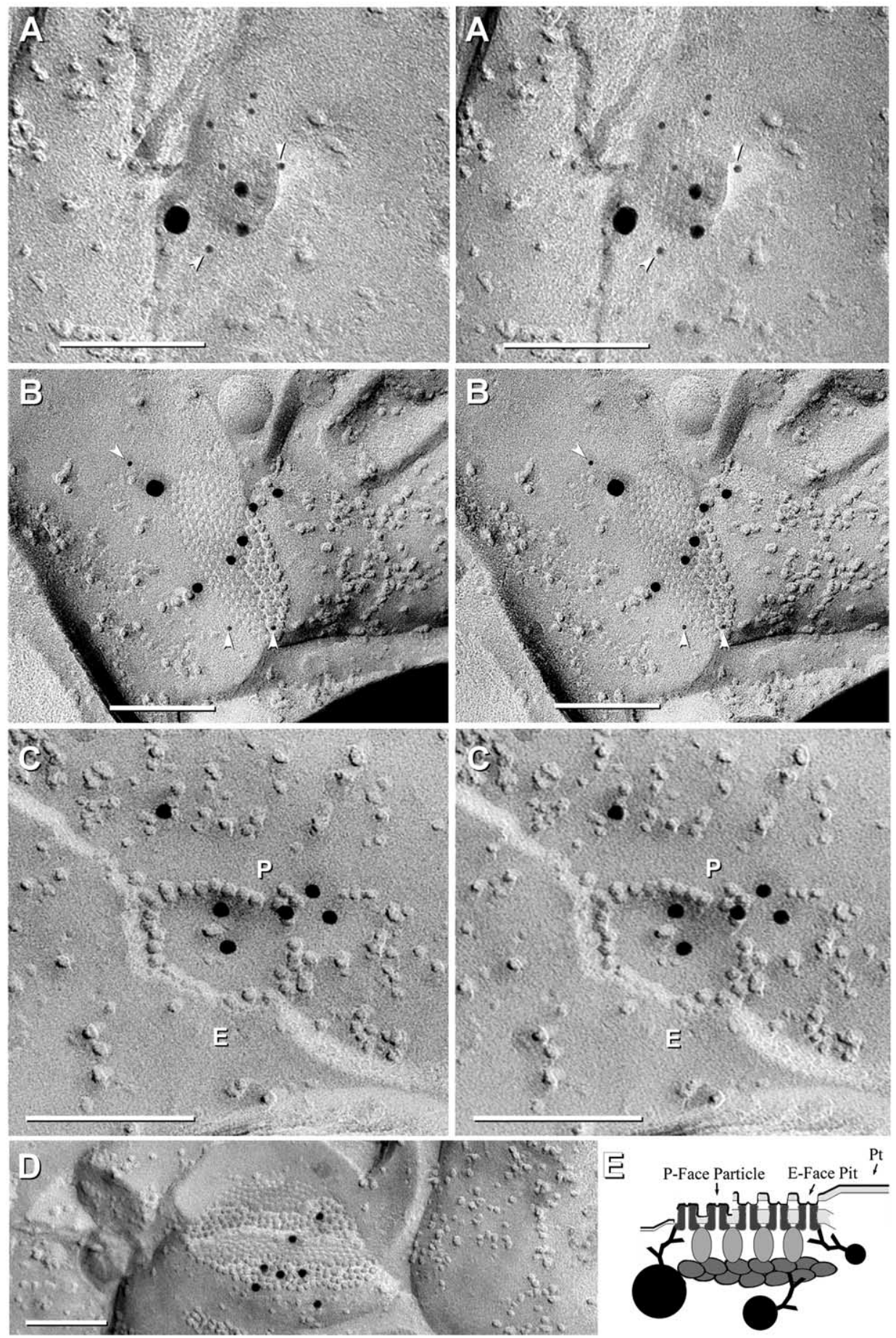

Figure 9. FRIL images showing colocalization of $(x 45$ with Z0-1 in rat IPL. A, Small crystalline plaque gap junction ( 41 connexons) double labeled for $C \times 45$ [ $6 \mathrm{~nm}$ gold beads (arrowheads) and one $18 \mathrm{~nm}$ gold bead] and for Z0-1 (two $12 \mathrm{~nm}$ gold beads). Stereoscopic viewing reveals that the gap junction E-face was almost fractured away, appearing as an attached flake canted above the underlying connexons, similar to that seen in Figure 6 B, above. $\boldsymbol{B}$, Medium-size partially crystalline plaque gap junction ( $\sim 154$ connexons) double labeled for $70-1$ (five $12 \mathrm{~nm}$ gold beads across the center) and for (X45 [three $6 \mathrm{~nm}$ gold beads (arrowheads) and one $18 \mathrm{~nm}$ gold bead, at the periphery]. C, Small "Q-shaped" string gap junction ( $\sim 34$ connexons, three as E-face pits) labeled for ZO-1 (six $12 \mathrm{~nm}$ gold beads) and for $(x 45$ ( $6 \mathrm{~nm}$ and $18 \mathrm{~nm}$ gold beads; none present). $0 \mathrm{ne} 12 \mathrm{~nm}$ gold bead that is outside the string of connexons may indicate either displacement during washing or the presence of Z0-1 outside the boundary of the gap junction. P, P-face; E, E-face. D, Medium plaque gap junction (341 connexons) labeled for Z0-1 (seven 12 nm gold beads, none for Cx45; same replica as $\boldsymbol{A}-\boldsymbol{C}$ ). Scale bars, $0.1 \mu \mathrm{m}$. E, Diagram showing proposed labeling of ZO-1 in the protein scaffolding that comprises the "cytoplasmic semi-dense matrix" (Sotelo and Korn, 1978). The dense matrix of scaffolding proteins may restrict penetration of primary and secondary antibody labels and thereby reduce labeling of connexons in the center of larger plaque gap junction (Fig. 3E).

\section{Interaction of $\mathrm{Cx} 45$ with $\mathrm{ZO}-1$ in HeLa cells and retina}

Cultured HeLa cells stably transfected with Cx45 were used to document $\mathrm{Cx} 45$ association with ZO-1. In control empty-vectortransfected cells, labeling of ZO-1 typically appeared as fine, intermittent puncta or as short, continuous strands of immunoflu- orescence at cell-cell contacts (Fig. 10A1), whereas Cx45 immunoreactivity was entirely absent (Fig. 10A2,A3). In Cx45HeLa cells, labeling of ZO-1 had a more dispersed appearance and was localized both at cell-cell contacts and intracellularly (Fig. 10 B1). Nearly all cells displayed labeling of Cx45 in puncta 


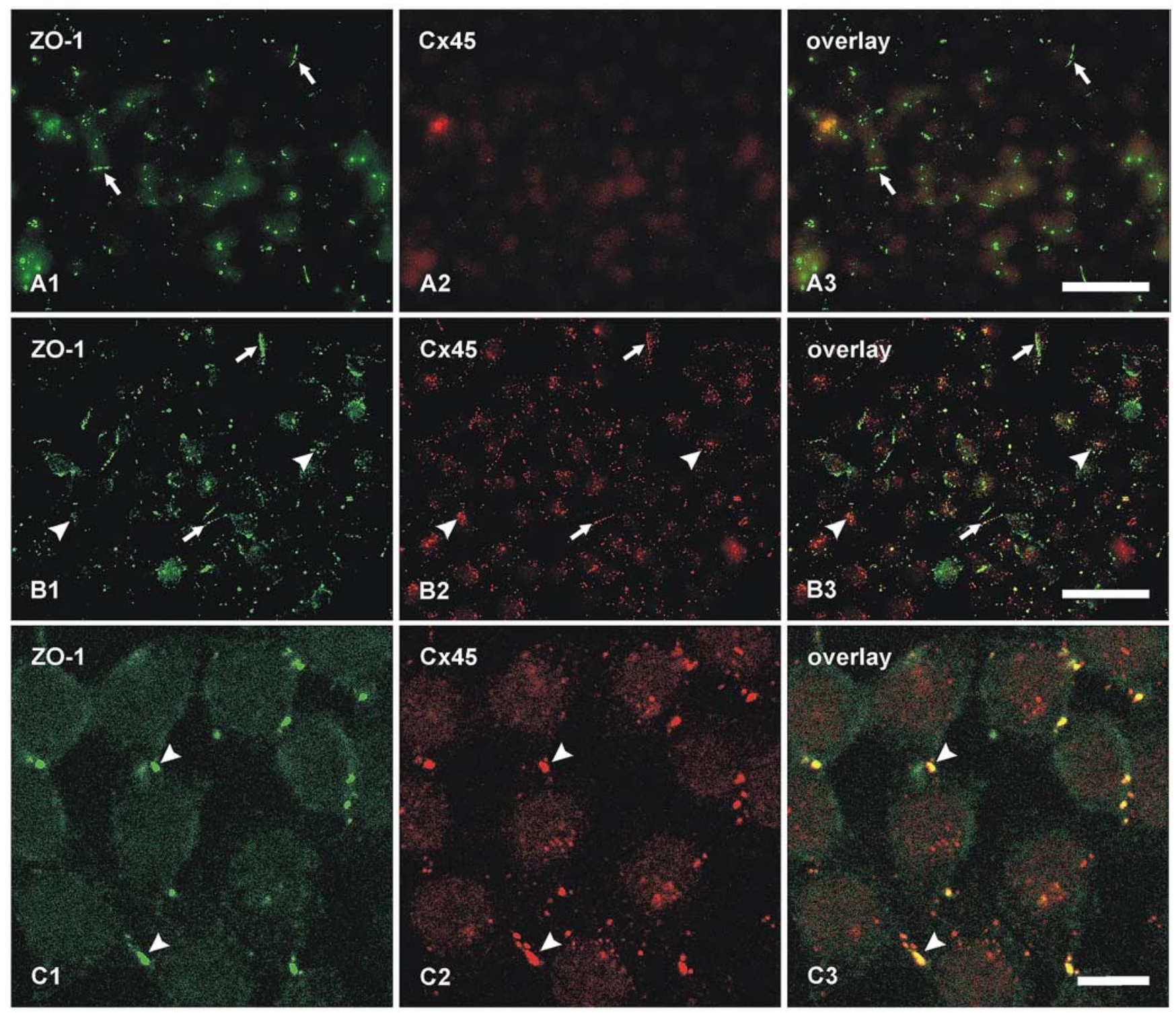

Figure 10. Double-immunofluorescence labeling of Z0-1 and (X45 in HeLa cell cultures. $\boldsymbol{A}$, Control empty vector-transfected HeLa cells showing labeling of Z0-1 at cell- cell contacts ( $\boldsymbol{A} \mathbf{1}$, arrows), and an absence of labeling for $\mathbf{C} 45$ (A2). B , HeLa cells stably transfected with $(x 45$. Immunolabeling is seen as linear strands of Z0-1-puncta (B1) and Cx45-puncta (B2) at cell- cell contacts (arrows), and as collections of puncta within cells (arrowheads). B3, Z0-1/Cx45 colocalization is evident at both locations. C, Confocal double immunofluorescence showing colocalization of punctate labeling for Z0-1 and Cx45 at contacts between Cx45-transfected HeLa cells (arrowheads). Scale bars: $A, B, 50 \mu \mathrm{m} ; C, 10 \mu \mathrm{m}$.

at contacts between cells and/or intracellularly (Fig. 10 B2). Double-immunofluorescence labeling indicated partial $\mathrm{Cx} 45 /$ ZO-1 overlap at both of these subcellular locations (Fig. 10 B3). Laser-scanning confocal double-immunofluorescence imaging further revealed that individual ZO-1-positive puncta at cell margins were immunopositive for Cx45 (Fig. 10C).

Immunoblotting and coimmunoprecipitation were used to confirm anti-Cx45 antibody specificity and to examine molecular interaction of $\mathrm{Cx} 45$ with ZO-1. In lysates of $\mathrm{Cx} 45$-HeLa cells examined using $12.5 \%$ gels, monoclonal anti-Cx45 (Millipore Bioscience Research Reagents) detected a band migrating at $\sim 45$ $\mathrm{kDa}$ (Fig. 11A, lane 2), whereas this band was absent in empty vector-transfected HeLa cells (Fig. $11 A$, lane 1). A similar comigrating band was detected in homogenates of retina (Fig. $11 \mathrm{~A}$, lane 4), but was absent in homogenates of liver (Fig. 11 $A$, lane 3), which was used as a negative control. After IP of ZO-1 from homogenates of retina using polyclonal anti-ZO-1, IP material probed with monoclonal anti-Cx45 was found to contain $\mathrm{Cx} 45$
(Fig. 11A, lane 6) comigrating with corresponding bands detected with monoclonal anti-Cx45 in retina (5\% of input protein in IP) and in Cx45-HeLa cells. Cx45 was not detectable in immunoblotted material after omission of anti-ZO-1 in the IP procedure (Fig. 11A, lane 5). A separate blot again shows a $\mathrm{Cx} 45$ band in retina (Fig. 11A, lane 7) and absence of this band after IP of ZO-1 from retina using anti-FLAG IgG as control antibody (Fig. $11 A$, lane 8). By Western blotting, we have previously shown the presence of $\mathrm{ZO}-1$ in retinal homogenates used as input for IP of ZO-1 (Li et al., 2004a). Immunoblotting of Cx45-HeLa cells using $12.5 \%$ gels and probing of membranes with polyclonal antiCx45 gave a similar detection of Cx45 (Fig. 11B, lane 1), which was absent in empty vector-transfected cells (Fig. $11 \mathrm{~B}$, lane 2 ). In $10 \%$ SDS gels, the polyclonal anti-Cx45 detected a doublet of bands (Fig. 11C), corresponding in molecular weight to previously reported phosphorylated and nonphosphorylated forms of Cx45 (van Veen et al., 2000). The polyclonal anti-Cx45 also detected Cx45 obtained from retina after IP of Cx45 with monoclo- 


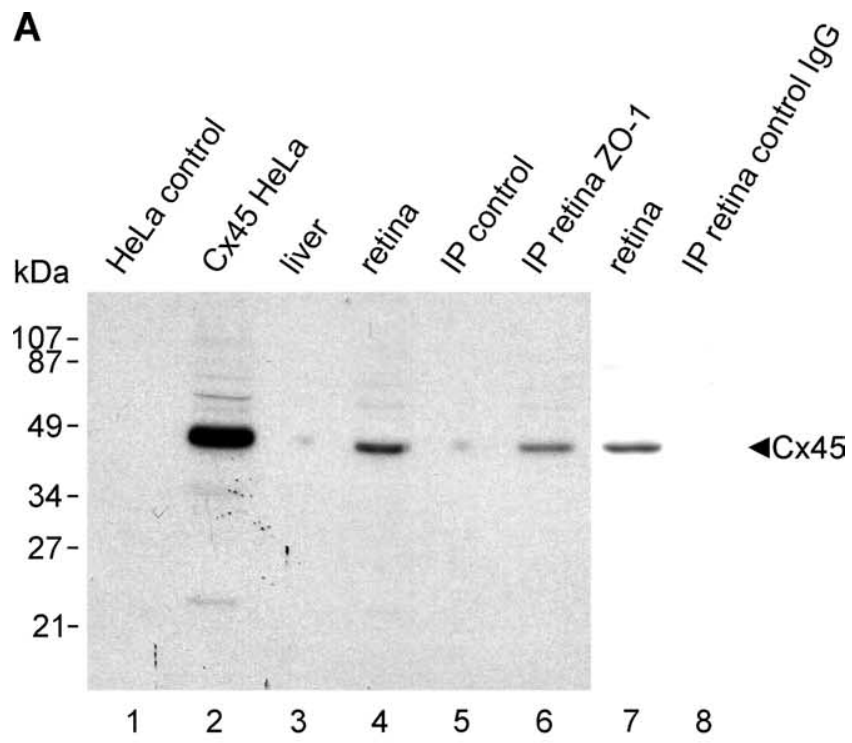

B

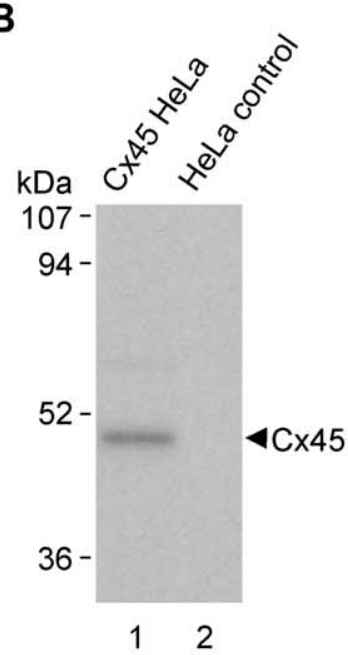

C

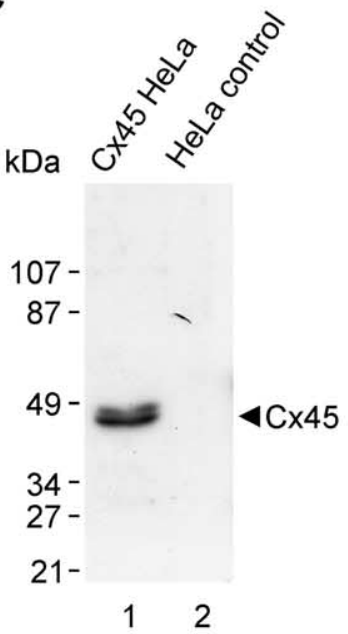

D

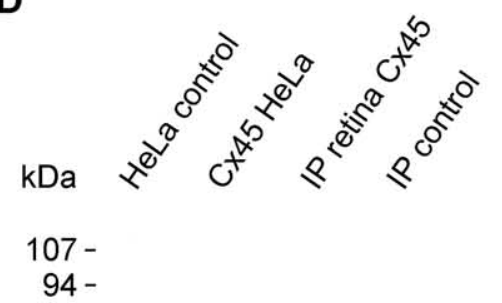

$52-$

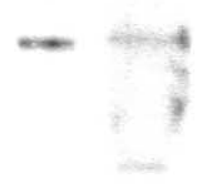

$36-$

$29-$

$\begin{array}{llll}1 & 2 & 3 & 4\end{array}$

Figure 11. Immunoblots demonstrating co-IP of $\mathrm{C} x 45 / 20-1$ from retina and detection of Cx45 with polyclonal anti-Cx45. $A$, C $x 45$ detection by monoclonal anti-Cx45 in lysates of $C \times 45-$ transfected HeLa cells (lane 2) and in homogenate of mouse retina (lanes 4 and 7), but not in empty vector-transfected HeLa cells (lane 1) or in liver (lane 3). After IP of Z0-1 from retina homogenate using polyclonal anti-Z0-1, monoclonal anti-Cx45 detects $\mathrm{Cx} 45$ (lane 6) comigrat-

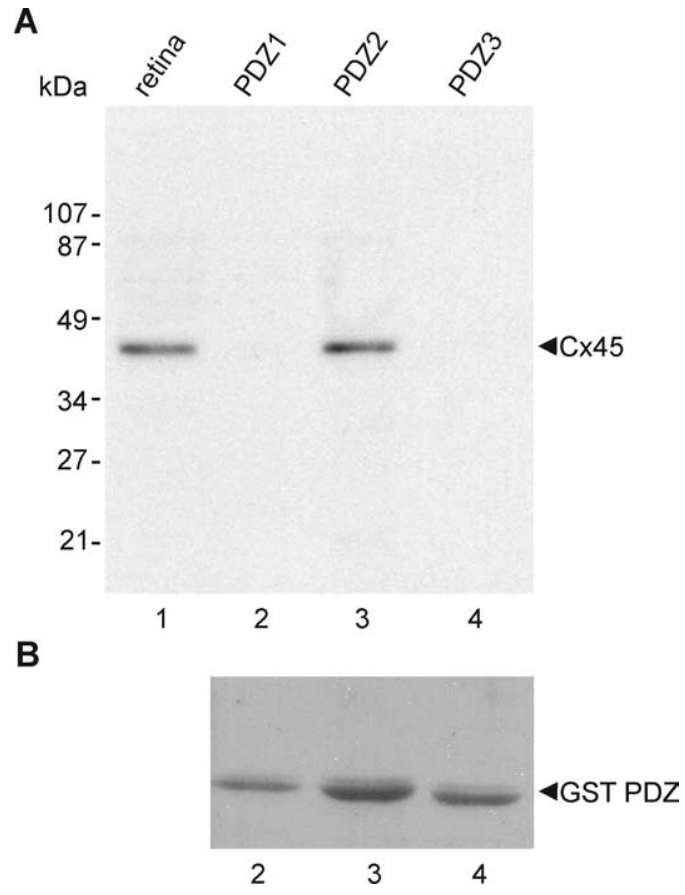

Figure 12. Immunoblots demonstrating CX45 pull-down with the PDZ2 domain of Z0-1. Lysates of $\mathrm{Cx} 45$-transfected HeLa cells were incubated with GST fusion proteins containing the PDZ1, PDZ2, or PDZ3 domain of Z0-1. A, Immunoblots of pull-down proteins probed with monoclonal anti-Cx45 show detection of $C x 45$ after pull-down with the PDZZ domain of ZO-1 (lane 3), but not after pull-down with the PDZ1 or PDZ3 domain of Z0-1 (lane 2 and 4). The CX45 band in lane 3 corresponds to detection of the same band in homogenate of retina (lane 1). $\boldsymbol{B}$, Blot in $A$ was stripped and reprobed with anti-GST antibody to show presence and equal loading of $\mathrm{PDZ}$ domain fusion proteins.

nal anti-Cx45 (Fig. 11D). These data demonstrated similar labeling specificity for all $\mathrm{Cx} 45$ antibodies tested.

Homogenates of mouse retina were used with fusion proteins containing GST linked separately to each of the three PDZ domains in ZO-1 for in vitro pull-down assays to examine direct binding of Cx45 to the PDZ domains of ZO-1. As shown by immunoblotting (Fig. 12A), eluates of protein from beads coupled to either the GST-PDZ1 (Fig. 12A, lane 2) or GST-PDZ3 (Fig. 12 A, lane 4) domain of ZO-1 were devoid of Cx45, whereas protein eluted from beads coupled to the GST-PDZ2 domain of ZO-1 (Fig. 12A, lane 3) contained Cx45, which migrated as a band corresponding to $\mathrm{Cx} 45$ detected in homogenates of mouse retina (Fig. $12 \mathrm{~A}$, lane 1). Stripping of the blot in Figure $12 \mathrm{~A}$ and reprobing with anti-GST antibody revealed equal loading of the three PDZ domain fusion proteins (Fig. 12 B). As a positive control for the functional binding capacity of the PDZ1 domain fusion protein, we have previously shown that this fusion protein

$\leftarrow$

ing with (x45 from retina homogentate (lane 4) and from (x45-transfected HeLa cells (lane 2), but not in IP material after omission of anti-Z0-1 during the IP procedure (lane 5) or after IP of Z0-1 from retina using anti-FLAG as control lgG (lane 8). B, C, Polyclonal anti-Cx45 detection of Cx45 as a single band using 12.5\% SDS-gel (B, lane 1) and as a doublet of bands using $10 \%$ SDS-gel ( $\boldsymbol{C}$, lane 1$)$ in lysates of $(x 45$-transfected HeLa cells, and absence of these bands in empty vector-transfected HeLa cells ( $\boldsymbol{B}, \boldsymbol{C}$, lane 2). $\boldsymbol{D}$, IP of $\mathrm{Cx} 45$ from retina with monoclonal anti-Cx45, showing detection of a Cx45 band with polyclonal anti-Cx45 in IP material (lane 3), corresponding to a $\mathrm{C} 45$ band detected by the polyclonal antibody in lysate from Cx45transfected HeLa cells (lane 2), and absence of the band in empty vector-transfected HeLa controls (lane 1) and after omission of monoclonal anti-Cx45 during the IP procedure (lane 4). 
was able to bind to the $\mathrm{C}$ terminus of $\mathrm{Cx} 36$ in pull-down assays (Li et al., 2004a,b).

\section{Co-IP of $\mathrm{Cx} 36$ with $\mathrm{Cx} 45$ from retina and HeLa cells}

Direct interaction of Cx36 with the PDZ1 domain of ZO-1 and interaction of $\mathrm{Cx} 45$ with the PDZ2 domain of $\mathrm{ZO}-1$, together with the presence of these two connexins in the same gap junctional hemiplaques, raised the possibility that these two connexins may be linked together by ZO-1 in a tripartite complex. Molecular association of $\mathrm{Cx} 36$ with $\mathrm{Cx} 45$ was therefore investigated by co-IP of these connexins from mouse retina and from HeLa cells cotransfected with either full-length Cx36 and Cx45 or with full-length Cx45 and truncated Cx36 (Cx36-tr) lacking the C terminus PDZ1 domain-binding motif. As shown in immunoblots probed with polyclonal anti-Cx36, IP of Cx45 with monoclonal anti-Cx45 resulted in detection of $\mathrm{Cx} 36$ in retinal IP material (Fig. 13A, lane 2) and in IP material from HeLa cells cotransfected with $\mathrm{Cx} 36 / \mathrm{Cx} 45$ (Fig. 13A, lane 1). In contrast, Cx36 was not detected in IP material from HeLa cells cotransfected with Cx45 and truncated Cx36 (Fig. 13A, lane 3), nor was it detected in IP material after omission of anti-Cx45 during the IP procedure (Fig. 12A, lane 4). We have previously shown by Western blotting that truncation of $\mathrm{Cx} 36$ by four C-terminal amino acids still allows $\mathrm{Cx} 36$ recognition by polyclonal anti-Cx36 antibody (Li et al., 2004a). Similar results were obtained using the reverse IP approach; IP of Cx36 with polyclonal anti-Cx36 resulted in detection of $\mathrm{Cx} 45$ in retinal IP material when probed with monoclonal anti-Cx45 (Fig. 13B, lane 2) and detection of Cx45 in IP material from Cx36/Cx45-cotransfected HeLa cells (Fig. 13B, lane 1). However, Cx45 was not detected in IP material from HeLa cells cotransfected with Cx45 and truncated Cx36 (Fig. 13B, lane 3) or in IP material after omission of anti-Cx36 during the IP procedure (Fig. 12B, lane 4). Additional control procedures are shown in supplemental Figure S2 (available at www.jneurosci.org as supplemental material). Specifically, input levels of Cx36 and Cx45 are demonstrated in lysates (5\%) of Cx36/Cx45-transfected and Cx36-tr/Cx45-transfected HeLa cells and retinal homogenates used for co-IP, and absence of $\mathrm{Cx} 45$ or Cx36 in IP material is shown after IP from each of the tissues using monoclonal and polyclonal anti-FLAG antibodies as control IgG.

\section{Discussion}

Establishing neuronal gap junctional coupling relationships in the retina is essential for understanding how rod scotopic and mesopic information is "piggybacked" onto the photopic cone pathway (Kolb, 1979; Strettoi et al., 1992; Vaney, 2002). Key to this goal is identification of connexin expression profiles of IPL neurons and determination of the connexin constituents of their gap junctions. A major new finding from FRIL and from SDSFRL double replicas, and one entirely unexpected based on current literature descriptions of neuron subtype-specific expression of $\mathrm{Cx} 36$ versus $\mathrm{Cx} 45$ in the IPL of rodent retina, is that $\mathrm{Cx} 36$ was nearly always colocalized with $\mathrm{Cx} 45$ in Cx45-containing freezefractured neuronal gap junctions. If a significant fraction of retinal gap junctions in IPL were to express only Cx45 in homotypic or in heterotypic hemiplaques, as proposed by others, FRIL would have revealed primarily or exclusively $\mathrm{Cx} 45$-single-labeled hemiplaques. This was not observed. Suggestions that $\mathrm{Cx} 45$ does not form functional heterotypic couplings with Cx36 (Teubner et al., 2000) were further supported by our coexpression experiments, which showed absence of heterotypic puncta in HeLa cells expressing Cx45 and Cx36. Overall, our finding that $87 \%$ of

\section{A IP of $\mathrm{Cx} 45$; probed with anti-Cx36}

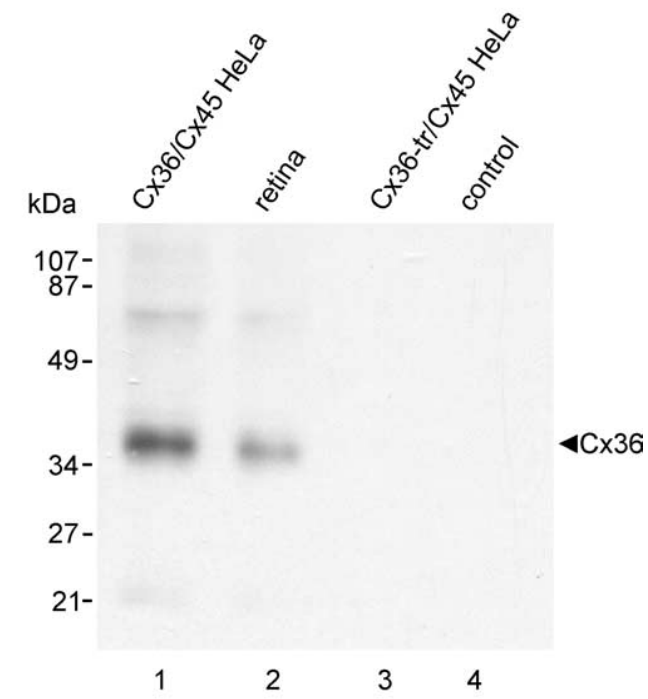

B IP of $\mathrm{C} \times 36$; probed with anti-Cx45

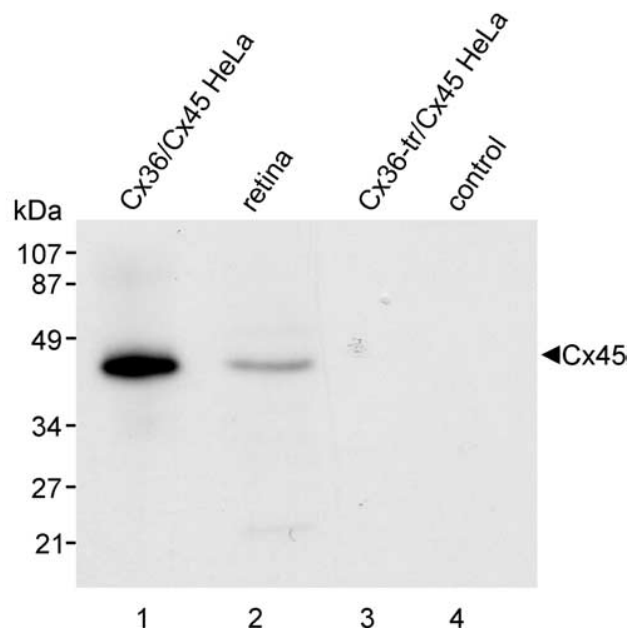

Figure 13. Co-IP of $\mathrm{C} \times 36$ with $\mathrm{C} \times 45$ from mouse retina and HeLa cells transfected with $\mathrm{C} \times 36$ and $\mathrm{C} \times 45 . \mathrm{A}$, Immunoblot showing detection of $\mathrm{C} \times 36$ after IP of $\mathrm{C} \times 45$ from mouse retina (lane 2) and from HeLa cells cotransfected with $\mathrm{C} \times 36 / \mathrm{C} \times 45$ (lane 1), and absence of $\mathrm{C} \times 36$ detection after IP of Cx45 from HeLa cells cotransfected with Cx45 and C-terminus-truncated Cx36 (lane 3) or after IP with omission of anti-Cx45 (lane 4). B, Immunoblot showing detection of $\mathrm{C}$ X45 after IP of $\mathrm{C} \times 36$ from mouse retina (lane 2) and from HeLa cells cotransfected with $\mathrm{C} \times 36 / \mathrm{C} \times 45$ (lane 1), and absence of $\mathrm{Cx} 45$ detection after IP of $\mathrm{Cx} 36$ from HeLa cells cotransfected with Cx45 and C-terminus-truncated Cx36 (lane 3) or after IP with omission of anti-Cx36 (lane 4).

Cx45-immunopositive puncta in the IPL were also immunopositive for $\mathrm{Cx} 36$ supports the extent of $\mathrm{Cx} 36 / \mathrm{Cx} 45$ colocalization across the IPL. Finally, Cx45 and Cx36 often had segregated but mirror distributions in both sides of opposing hemiplaques, forming definitive bihomotypic rather than heterotypic gap junctions, and moreover, that $\mathrm{Cx} 45$ and $\mathrm{Cx} 36$ were primarily or exclusively in homomeric connexons. These results raise several issues regarding current literature on connexin biology in the IPL.

First, Cx45-positive immunofluorescent puncta in the IPL were reported never to overlap (0\%) with Cx36-positive puncta (Han and Massey, 2005) or to exhibit 30\% colocalization (Dedek et al., 2006), both contrasting with $87 \%$ immunofluorescence colocalization found here. Likewise, the OFF sublamina was reported to be devoid of $\mathrm{Cx} 45$ immunofluorescence (Güldenagel et 
al., 2000) or to contain a very low density of Cx45 (Maxeiner et al., 2005), whereas we observed relatively abundant Cx45 puncta in the OFF sublamina. Also contradictory, Feigenspan et al. (2001) noted that the heterologous gap junctions between AII amacrine cells and ON cone bipolar cells "appear to be heterotypic because ON cone bipolar cells do not express Cx36," whereas Deans et al. (2002) stated that "Cx36 is expressed by ON CBs coupled to AII amacrine cells." In contrast, Maxeiner et al. (2005) stated that "all four classes of OFF cone bipolar cells express Cx45," and acknowledged "the possibility that both Cx36 and Cx45 are expressed by the same bipolar cell." We attribute these differences in immunofluorescence detection to fixationdependent reduction in antibody labeling, as evidenced by a lower percentage of $\mathrm{Cx} 36 / \mathrm{Cx} 45$ colocalization after increased fixation ( 45 vs $87 \%)$.

Second, reporter-based approaches to cell-type identification of connexin expression in IPL suggested that neurons expressing Cx45 represent entirely different populations than those expressing $\mathrm{Cx} 36$. Thus, Dedek et al. (2006) attributed their 30\% colocalization of Cx36 with $\mathrm{Cx} 45$ to each connexin exclusively in opposite sides of opposed hemiplaques, which they proposed to represent heterotypic Cx45cone bipolar to Cx36-AII amacrine cell gap junctions. Although Cx45 lacks dye-coupling competence with Cx36 in HeLa cells transfected with these connexins (Teubner et al., 2000), it was suggested that HeLa cells might lack essential accessory proteins that otherwise permit the hypothesized functional Cx36/Cx45 coupling in IPL neurons (Maxeiner et al., 2005). Because Teubner et al. (2000) had not assayed for connexin colocalization, we investigated similar connexin-transfected HeLa cell lines and showed that they form immunopositive plaques containing homotypic Cx36/Cx36, Cx43/ $\mathrm{Cx} 43$, and $\mathrm{Cx} 45 / \mathrm{Cx} 45$ puncta, as well as heterotypic $\mathrm{Cx} 43 / \mathrm{Cx} 45$ puncta at cell-cell abutments, but did not form heterotypic Cx45/ Cx36 puncta. Instead, immunofluorescence colocalization of Cx45+Cx36 in HeLa cell contacts required that both cells simultaneously coexpress both proteins. Because HeLa cells contain requisite scaffolding and targeting proteins to allow separate formation of Cx45-containing and Cx36-containing gap junctions, as well as Cx45+Cx36 bihomotypic gap junctions, Cx45 appears unable to form heterotypic puncta with Cx36 in these cells.

Third, our combined results imply that Cx45 and Cx36 are transported to and stabilized in retinal gap junctions by common targeting and scaffolding proteins. Cx36 binds to the PDZ1 domain of ZO-1 (Li et al., 2004a,b), and here we showed Cx45/ZO-1 coassociation in mouse retina and interaction of $\mathrm{Cx} 45$ with the PDZ2 domain, which had not been determined previously (Kausalya et al., 2001; Laing et al., 2001; Thomas et al., 2002). Significantly, Cx45/ZO-1 colocalization persisted in IPL from Cx36 ko mice, indicating that this colocalization was not simply attributable to ZO-1 association with $\mathrm{Cx} 36$ at $\mathrm{Cx} 36 / \mathrm{Cx} 45$-containing gap junctions. Presence of all three proteins in IPL gap junctions and their co-IP suggest an essential targeting and scaffolding role for $\mathrm{ZO}-1$ in $\mathrm{Cx} 45+\mathrm{Cx} 36-$ containing gap junctions. With nine members of the connexin family of proteins reported to associate with ZO-1 (Giepmans, 2004; Li et al., 2004a,b,c; Penes et al., 2005), a regulatory role for ZO-1 at gap junctions is emerging (Li et al., 2004a,b,c; Hunter et al., 2005; Laing et al., 2005; Akoyev and Takemoto, 2007). Binding of Cx36 and Cx45 to different ZO-1 PDZ domains suggests that ZO-1 may simultaneously interact with $\mathrm{Cx} 36$ and $\mathrm{Cx} 45$ in a tripartite manner, thereby tethering the two connexins within gap junctions. A critical role of $\mathrm{ZO}-1$ in mediating this association was indicated by abolition of Cx36/Cx45 co-IP after removal of the C-terminal 4 aa residues of $\mathrm{Cx} 36$ (this report), which are required for the interaction of $\mathrm{Cx} 36$ with the PDZ1 domain of ZO-1 (Li et al., 2004a).
Fourth, heterotypic gap junctional coupling between Cx36expressing AII amacrine cells and Cx45-expressing ON-cone bipolar cells was advanced as a key element in the rod pathway, based on substantial alteration of electroretinograms in Cx45 ko mice (Maxeiner et al., 2005). We found that absence of Cx36 in Cx36 ko mice was accompanied by $25 \%$ reduction of Cx45puncta in IPL. Our results, combined with those of Maxeiner et al. (2005), suggest that reduced coupling observed in this pathway after Cx36 ko (Güldenagel et al., 2001; Deans et al., 2002) may be attributable not only to loss of Cx36, but also to a small reduction in $\mathrm{Cx} 45$ expression or trafficking, which may require Cx45 cobinding with $\mathrm{Cx} 36$ and $\mathrm{ZO}-1$ for optimum targeting and/or stability. Because $\mathrm{Cx} 45$-containing gap junctions appear to obligately contain $\mathrm{Cx} 36$, knock-out of $\mathrm{Cx} 45$ from these otherwise bihomotypic gap junctions also might alter the function and/or stability of the Cx36 that remains in the absence of Cx45.

Fifth, previous studies suggested that most if not all neurons synapsing in the IPL separately express only one or the other connexin isoform (Han and Massey, 2005; Dedek et al., 2006). However, the methods used, including in situ hybridization, single-cell RT-PCR, lacZ reporter expression [by a nonconventional method (Schubert et al., 2005)], or expression of cytoplasmic EGFP as genetic markers (Han and Massey, 2005; Lin et al., 2005; Maxeiner et al., 2005; Dedek et al., 2006), have significant probabilities of both "false-positive" and "false-negative" detection; and as in all techniques, efforts to minimize false positives increase the probability of false negatives by altering the threshold of signal detection. For example, by reducing amplification of lacZ signal so that $\mathrm{Cx} 45$-positive cells had from one to a maximum of three lacZ cytoplasmic "dots" (Schubert et al., 2005), weakly expressing cells may have had inadequate amplification to produce a detectable dot, leading to false negatives. Likewise, none of the mRNA-detection methods measure different expression levels that are implied by vastly different sizes (and numbers) of Cx36- versus Cx45/Cx36-containing gap junctions [4-2500 connexons (Kamasawa et al., 2006)]. Our data imply that AII amacrine cells, reportedly expressing only Cx36 (Maxeiner et al., 2005), that couple to $\mathrm{Cx} 45 / \mathrm{Cx} 36$-coexpressing cells (e.g., cone bipolar cells) must form only Cx36/Cx36 monohomotypic couplings, or that AII amacrine cells must also synthesize Cx45 to form bihomotypic gap junctions, but with Cx45 synthesized at an amount sufficiently low as to have previously gone undetected. Conversely, if AII amacrine cells truly lack $\mathrm{Cx} 45$, the detection of $\mathrm{Cx} 45$-immunofluorescent puncta at apparent cell contacts involving AII amacrine cells must be at tripartite contacts between two other $\mathrm{Cx} 45 / \mathrm{Cx} 36$-coexpressing cell processes that are not separately resolvable by light microscopy from the closely associated AII amacrine cell. Such triadic structural arrangements [Kolb (1979), her Fig. 29b] could also account for the reduction in glycine transfer from AII amacrine cells to cone bipolar cells in both Cx36 and Cx45 ko mice (Güldenagel et al., 2001; Maxeiner et al., 2005) if the intermediary neuron expressing Cx36+Cx45 were coupled to glycinergic AII amacrine cells solely by Cx36containing gap junctions and serially to the nonglycinergic bipolar cells by bihomotypic Cx45/Cx36 gap junctions. Additionally, this would require that $\mathrm{Cx} 45$ ko also disrupt $\mathrm{Cx} 45 / \mathrm{Cx} 36$ bihomotypic couplings.

Overall, our results document that virtually all Cx45containing gap junctions occur between cell pairs in which both cells coexpress and cotarget $\mathrm{Cx} 45$ and $\mathrm{Cx} 36$, forming bihomotypic gap junctions. Thus, interpretation of future coupling experiments involving $\mathrm{Cx} 45$-expressing retinal neurons must consider the restricted range of sizes of $\mathrm{Cx} 45$-containing gap junctions compared with homotypic Cx36 gap junctions, rather than ascribing observed differences in coupling to heterotypic 
versus homotypic coupling. For example, gating of $\mathrm{Cx} 45$ (but not Cx36) is voltage sensitive, and Cx45 has threefold greater conductance (Söhl et al., 2005), potentially allowing differential regulation of gap junction electrical and/or metabolic coupling. Consequently, subcellular regulation of the ratios and abundance of these two connexins in individual gap junctions would allow for finer analog control than available from monohomotypic $\mathrm{Cx} 36$ or $\mathrm{Cx} 45$ gap junctions, as well as provide a novel mechanism for plasticity of electrical synapses.

\section{References}

Akoyev V, Takemoto DJ (2007) ZO-1 is required for protein kinase C gamma-driven disassembly of connexin43. Cell Signal 19:958-967.

Balda MS, Garrett MD, Matter K (2003) The ZO-1-associated Y-box factor ZONAB regulates epithelial cell proliferation and cell density. J Cell Biol 160:423-432.

Chalcroft JP, Bullivant S (1970) An interpretation of liver cell membrane and junction structure based on observation of freeze-fracture replicas of both sides of the fracture. J Cell Biol 47:49-60.

Chen VC, Li X, Perreault H, Nagy JI (2006) Interaction of zonula occludens-1 (ZO-1) with alpha-actinin-4: application of functional proteomics for identification of PDZ domain-associated proteins. J Proteome Res 5:2123-2134.

Ciolofan C, Li XB, Olson C, Kamasawa N, Gebhardt BR, Yasumura T, Morita M, Rash JE, Nagy JI (2006) Association of connexin36 and zonula occludens- 1 with zonula occludens- 2 and the transcription factor zonula occludens-1-associated nucleic acid-binding protein at neuronal gap junctions in rodent retina. Neuroscience 140:433-451.

Deans MR, Volgyi B, Goodenough DA, Bloomfield SA, Paul DL (2002) Connexin 36 is essential for transmission of rod-mediated visual signals in the mammalian retina. Neuron 36:703-712.

Dedek K, Schultz K, Pieper M, Dirks P, Maxeiner S, Willecke K, Weiler R, Janssen-Bienhold U (2006) Localization of heterotypic gap junctions composed of connexin 45 and connexin36 in the rod pathway of the mouse retina. Eur J Neurosci 24:1675-1686.

Dinchuk JE, Johnson TJA, Rash JE (1987) Postreplication labeling of E-leaflet molecules: membrane immunoglobulins localized in sectioned labeled replicas examined by TEM and HVEM. J Electron Microsc Tech 7:1-16.

Elfgang C, Eckert R, Lichtenberg-Fraté H, Butterweck A, Traub O, Klein RA, Hülser DF, Willecke K (1995) Specific permeability and selective formation of gap junction channels in connexin-transfected HeLa cells. J Cell Biol 129:805-817.

Evans WH, Martin PEM (2002) Gap junctions: structure and function. Mol Membr Biol 19:121-136.

Feigenspan A, Teubner B, Willecke K, Weiler R (2001) Expression of neuronal connexin36 in AII amacrine cells of the mammalian retina. J Neurosci 21:230-239.

Fujimoto K (1995) Freeze-fracture replica electron microscopy combined with SDS digestion for cytochemical labeling of integral membrane proteins. Application to the immunogold labeling of intercellular junctional complexes. J Cell Sci 108:3443-3449.

Fujimoto K (1997) SDS-digested freeze-fracture replica labeling electron microscopy to study the two-dimensional distribution of integral membrane proteins and phospholipids in biomembranes: practical procedure, interpretation and application. Histochem Cell Biol 107:87-96.

Fujimoto K, Nagafuchi A, Tsukita S, Kuraoka A, Ohokuma A, Shibata Y (1997) Dynamics of connexins, E-cadherin, and $\alpha$-catenin on cell membranes during gap junction formation. J Cell Sci 110:311-322.

Gaietta G, Deerinck TJ, Adams SR, Bouwer J, Tour O, Laird DW, Sosinsky GE, Tsien RY, Ellisman MH (2002) Multicolor and electron microscopic imaging of connexin trafficking. Science 296:503-507.

Ghosh KK, Bujan S, Haverkamp S, Feigenspan A, Wässle H (2004) Types of bipolar cells in the mouse retina. J Comp Neurol 469:70-82.

Giepmans BN (2004) Gap junctions and connexin-interacting proteins. Cardiovasc Res 62:233-245.

Gruijters WTM, Kistler J, Bullivant S, Goodenough DA (1987) Immunolocalization of MP70 in lens fiber 16-17-nm intercellular junctions. J Cell Biol 104:565-572.

Güldenagel M, Söhl G, Plum A, Traub O, Teubner B, Weiler R, Willecke K (2000) Expression patterns of connexin genes in mouse retina. J Comp Neurol 425:193-201.
Güldenagel M, Ammermüller J, Feigenspan A, Teubner B, Degen J, Söhl G, Willecke K, Weiler R (2001) Visual transmission deficits in mice with targeted disruption of the gap junction gene connexin36. J Neurosci 21:6036-6044.

Han Y, Massey SC (2005) Electrical synapses in retinal ON cone bipolar cells: subtype-specific expression of connexins. Proc Natl Acad Sci U S A 102:13313-13318.

Huber R, Deisenhofer J, Colman PM, Matsushima M, Palm W (1976) Crystallographic structure studies of an IgG molecule and an Fc fragment. Nature 264:415-420.

Hunter AW, Barker RJ, Zhu C, Gourdie RG (2005) Zonula occludens-1 alters connexin 43 gap junction size and organization by influencing channel accretion. Mol Biol Cell 16:5686-5698.

Kamasawa N, Sik A, Morita M, Yasumura T, Davidson KGV, Nagy JI, Rash JE (2005) Connexin47 and connexin32 in gap junctions of oligodendrocyte somata, myelin sheaths, paranodal loops, and Schmidt-Lanterman incisures: implications for ionic homeostasis and potassium siphoning. Neuroscience 136:65-86.

Kamasawa N, Furman CS, Davidson KGV, Sampson JA, Magnie AR, Gebhardt BR, Kamasawa M, Yasumura T, Zumbrunnen JR, Pickard GE, Nagy JI, Rash JE (2006) Abundance and ultrastructural diversity of neuronal gap junctions in the OFF and ON sublaminae of the inner plexiform layer of rat and mouse retina. Neuroscience 142:1093-1117.

Kausalya PJ, Reichert M, Hunziker W (2001) Connexin45 directly binds to ZO-1 and localizes to the tight junction region in epithelial MDCK cells. FEBS Lett 505:92-96.

Kolb H (1979) The inner plexiform layer in the retina of the cat: electron microscopic observations. J Neurocytol 8:295-329.

Kolb H, Famiglietti EV (1974) Rod and cone pathways in the inner plexiform layer of cat retina. Science 186:47-49.

Kosaka T, Kosaka K (2003) Neuronal gap junctions in the rat main olfactory bulb, with special reference to intraglomerular gap junctions. Neurosci Res 45:189-209.

Krüger O, Plum A, Kim J-S, Winterhager E, Maxeiner S, Hallas G, Kirchhoff S, Traub O, Lamers WH, Willecke K (2000) Defective vascular development in connexin45-deficient mice. Development 127:4179-4193.

Laing JG, Manley-Markowski RN, Koval M, Civitelli R, Steinberg TH (2001) Connexin 45 interacts with zonula occludens- 1 and connexin 43 in osteoblastic cells. J Biol Chem 276:23051-23055.

Laing JG, Chou BC, Steinberg TH (2005) ZO-1 alters the plasma membrane localization and function of $\mathrm{Cx} 43$ in osteoblastic cells. J Cell Sci 118:2167-2176.

Li X, Simard JM (2001) Connexin45 gap junction channels in rat cerebral vascular smooth muscle cells. Am J Physiol Heart Circ Physiol 281:H1890-H1898.

Li X, Olson C, Lu S, Kamasawa N, Yasumura T, Rash JE, Nagy JI (2004a) Neuronal connexin36 association with zonula occludens-1 protein (ZO-1) in mouse brain and interaction with the first PDZ domain of ZO-1. Eur J Neurosci 19:2132-2146.

Li X, Olson C, Lu S, Nagy JI (2004b) Association of connexin36 with zonula occludens- 1 in HeLa cells, $\beta$ TC- 3 cells, pancreas and adrenal gland. Histochem Cell Biol 122:485-498.

Li X, Ionescu AV, Lynn BD, Lu S, Kamasawa N, Morita M, Davidson KG, Yasumura T, Rash JE, Nagy JI (2004c) Connexin47, connexin29 and connexin 32 co-expression in oligodendrocytes and $\mathrm{Cx} 47$ association with zonula occludens-1 (ZO-1) in mouse brain. Neuroscience 126:611-630.

Lin B, Jakobs TC, Masland RH (2005) Different functional types of bipolar cells use different gap-junctional proteins. J Neurosci 25:6696-6701.

Masugi-Tokita M, Tarusawa E, Watanabe M, Molnár E, Fujimoto K, Shigemoto R (2007) Number and density of AMPA receptors in individual synapses in the rat cerebellum as revealed by SDS-digested freeze-fracture replica labeling. J Neurosci 27:2135-2144.

Maxeiner S, Dedek K, Janssen-Bienhold U, Ammermüller J, Brune H, Kirsch T, Pieper M, Degen J, Krüger O, Willecke K, Weiler R (2005) Deletion of connexin 45 in mouse retinal neurons disrupts the rod/cone signaling pathway between AII amacrine and ON cone bipolar cells and leads to impaired visual transmission. J Neurosci 25:566-576.

Meier C, Dermietzel R, Davidson KGV, Yasumura T, Rash JE (2004) Connexin32-containing gap junctions in Schwann cells at the internodal zone of partial myelin compaction and in Schmidt-Lanterman incisures. J Neurosci 24:3186-3198. 
Nagy JI, Dudek FE, Rash JE (2004) Update on connexins and gap junctions in neurons and glia in the nervous system. Brain Res Rev 47:191-215.

Nielsen PA, Beahm DL, Giepmans BN, Baruch A, Hall JE, Kumar NM (2002) Molecular cloning, functional expression, and tissue distribution of a novel human gap junction-forming protein, connexin31.9. Interaction with zona occludens protein-1. J Biol Chem 277:38272-38283.

Nielsen PA, Baruch A, Shestopalov VI, Giepmans BN, Dunia I, Benedetti EL, Kumar NM (2003) Lens connexins Cx46 and Cx50 interact with Zonula Occludens Protein-1 (ZO-1). Mol Biol Cell 14:2470-2481.

Penes MC, Li X, Nagy JI (2005) Expression of zonula occludens-1 (ZO-1) and the transcription factor $\mathrm{ZO}-1$-associated nucleic acid-binding protein $(\mathrm{ZONAB} / \mathrm{MsY} 3)$ in glial cells and co-localization at oligodendrocyte and astrocyte gap junctions in mouse brain. Eur J Neurosci 22:404-418.

Rackauskas M, Kreuzberg MM, Pranevicius M, Willecke K, Verselis VK, Bukauskas FF (2007) Gating properties of heterotypic gap junction channels formed of connexins 40, 43 and 45. Biophys J 92:1952-1965.

Rash JE, Yasumura T (1999) Direct immunogold labeling of connexins and aquaporin 4 in freeze-fracture replicas of liver, brain and spinal cord: factors limiting quantitative analysis. Cell Tissue Res 296:307-321.

Rash JE, Dillman RK, Morita M, Whalen LR, Guthrie PB, Fay-Guthrie D, Wheeler DW (1995) Grid-mapped freeze fracture: correlative confocal laser scanning microscopy and freeze-fracture electron microscopy of preselected cells in tissue slices. In: Rapid freezing, freeze fracture, and deep etching (Severs NJ, Shotton DM, eds), pp 127-150. New York: Wiley.

Rash JE, Dillman RK, Bilhartz BL, Duffy HS, Whalen LR, Yasumura T (1996) Mixed synapses discovered and mapped throughout mammalian spinal cord. Proc Natl Acad Sci U S A 93:4235-4239.

Rash JE, Duffy HS, Dudek FE, Bilhartz BL, Whalen LR, Yasumura T (1997) Grid-mapped freeze-fracture analysis of gap junctions in gray and white matter of adult rat central nervous system, with evidence for a "panglial syncytium" that is not coupled to neurons. J Comp Neurol 388:265-292.

Rash JE, Yasumura T, Dudek FE, Nagy JI (2001) Cell-specific expression of connexins and evidence of restricted gap junctional coupling between glial cells and between neurons. J Neurosci 15:1983-2000.

Rash JE, Pereda A, Kamasawa N, Furman CS, Yasumura T, Davidson KGV, Dudek FE, Olson C, Li X, Nagy JI (2004) High-resolution proteomic mapping in the vertebrate central nervous system: close proximity of connexin35 to NMDA glutamate receptor clusters and co-localization of connexin 36 with immunoreactivity for zonula occludens protein-1 (ZO1). J Neurocytol 33:131-151.

Rash JE, Olson CO, Davidson KGV, Yasumura T, Kamasawa N, Nagy JI (2007a) Identification of connexin36 in gap junctions between neurons in rodent locus coeruleus. Neuroscience 147:938-956.

Rash JE, Olson CO, Pouliot WA, Davidson KGV, Yasumura T, Furman CS,
Royer S, Kamasawa N, Nagy JI, Dudek FE (2007b) Connexin36, miniature neuronal gap junctions, and limited electrotonic coupling in rodent suprachiasmatic nucleus. Neuroscience 149:350-371.

Schubert T, Maxeiner S, Krüger O, Willecke K, Weiler R (2005) Connexin45 mediates gap junctional coupling of bistratified ganglion cells in the mouse retina. J Comp Neurol 490:29-39.

Söhl G, Willecke K (2003) An update on connexin genes and their nomenclature in mouse and man. Cell Commun Adhes 10:173-180.

Söhl G, Maxeiner S, Willecke K (2005) Expression and functions of neuronal gap junctions. Nat Rev Neurosci 6:191-200.

Sotelo C, Korn H (1978) Morphological correlates of electrical and other interactions through low-resistance pathways between neurons of the vertebrate central nervous system. Int Rev Cytol 55:67-107.

Steere RL, Erbe EF (1983) Supporting freeze-etch specimens with 'Lexan' while dissolving biological remains in acids. Proc Elec Microsc Soc Am 41:618-619.

Strettoi E, Raviola E, Dacheux RF (1992) Synaptic connections of the narrow-field, bistratified rod amacrine cell (AII) in the rabbit retina. J Comp Neurol 325:152-168.

Tanaka J, Matsuzaki M, Tarusawa E, Momiyama A, Molnar E, Kasai H, Shigemoto R (2005) Number and density of AMPA receptors in single synapses in immature cerebellum. J Neurosci 25:799-807.

Teubner B, Degen J, Söhl G, Güldenagel M, Bukauskas FF, Trexler EB, Verselis VK, De Zeeuw CI, Lee CG, Kozak CA, Petrasch-Parwez E, Dermietzel R, Willecke K (2000) Functional expression of the murine connexin 36 gene coding for a neuron-specific gap junctional protein. J Membr Biol 176:249-262.

Thomas MA, Huang S, Cokoja A, Riccio O, Staub O, Suter S, Chanson M (2002) Interaction of connexins with protein partners in the control of channel turnover and gating. Biol Cell 94:445-456.

Valentine RC, Green NM (1967) Electron microscopy of an antibodyhapten complex. J Mol Biol 27:615-617.

van den Pol AN, Ghosh PK, Liu RJ, Li Y, Aghajanian GK, Gao XB (2002) Hypocretin (orexin) enhances neuron activity and cell synchrony in developing mouse GFP-expressing locus coeruleus. J Physiol 541:169-185.

Vaney DI (2002) Retinal neurons: cell types and coupled networks. Prog Brain Res 136:239-254.

Vaney DI, Weiler R (2000) Gap junctions in the eye: evidence for heteromeric, heterotypic and mixed-homotypic interactions. Brain Res Rev 32:115-120.

van Veen TA, van Rijen HV, Jongsma HJ (2000) Electrical conductance of mouse connexin 45 gap junction channels is modulated by phosphorylation. Cardiovasc Res 46:496-510. 